\title{
Dinutuximab Synergistically Enhances the Cytotoxicity of Natural Killer Cells to Retinoblastoma Through the Perforin-Granzyme B Pathway
}

This article was published in the following Dove Press journal: OncoTargets and Therapy

\author{
Huixue Wang ${ }^{1-3, *}$ \\ Jie Yang ${ }^{1,2, *}$ \\ Hui Pan $1,2, *$ \\ Mei Chee Tai iD ${ }^{3}$ \\ Mohamed $\mathrm{H}$ Maher (D) 3,4 \\ Renbing Jia ${ }^{1,2}$ \\ Shengfang Ge (iD ${ }^{1,2}$ \\ Linna Lu ${ }^{1,2}$ \\ 'Department of Ophthalmology, Shanghai \\ Ninth People's Hospital, Shanghai Jiao \\ Tong University School of Medicine, \\ Shanghai, People's Republic of China; \\ ${ }^{2}$ Shanghai Key Laboratory of Orbital \\ Diseases and Ocular Oncology, Shanghai, \\ People's Republic of China; ${ }^{3}$ Department \\ of Translational Molecular Pathology, The \\ University of Texas MD Anderson Cancer \\ Center, Houston, TX, USA; ${ }^{4}$ Cancer \\ Biology Department, South Egypt Cancer \\ Institute, Assiut University, Assiut, Egypt
}

*These authors contributed equally to this work
Correspondence: Shengfang Ge; Linna Lu Shanghai Key Laboratory of Orbital Diseases and Ocular Oncology, No. 12, Lane 833, Zhizaoju Road, Huangpu

District, Shanghai 20000I, People's

Republic of China

Tel +86 I880I969540

Email geshengfang@sjtu.edu.cn;

drlulinna@I26.com
Purpose: Conventional chemotherapy and enucleation usually fail to cure advanced retinoblastoma. We investigated the retinoblastoma immune microenvironment and the efficacy of the combination of dinutuximab and CD16-expressing NK-92MI (NK-92MI ${ }^{\mathrm{hCD} 16-\mathrm{GFP}}$ ) cells on retinoblastoma cells in this study.

Patients and Methods: Immunohistochemistry and flow cytometry (FC) were performed to assess the expression level of GD2 in retinoblastoma tissues and cells. Gene set enrichment analysis (GSEA), immunohistochemisrztry and immunocytochemistry were conducted to assess the retinoblastoma immune microenvironment and the integrity of the blood-retinal barrier (BRB). After overexpressing CD16 in NK-92MI cells, fluorescence-activated cell sorting (FACS) was applied to select the positive subpopulation. LDH assays and FC were used to detect LDH release and apoptosis in retinoblastoma cells subjected to a combination of dinutuximab and NK92MI ${ }^{\text {hCD16-GFP }}$ cells. Finally, the release of perforin-granzyme B and the expression of CD107a in NK-92MI ${ }^{\text {hCD16-GFP }}$ stimulated by retinoblastoma cells were assessed via enzyme-linked immunosorbent assays (ELISAs) and FC in the presence of dinutuximab or an isotype control.

Results: GD2 was heterogeneously expressed in retinoblastoma tissues and cell lines and positively correlated with proliferation and staging. GSEA revealed the immunosuppressive status of retinoblastoma microenvironment. The immune cell profile of retinoblastoma tissues and vitreous bodies suggested BRB destruction. LDH release and apoptosis in retinoblastoma cells caused by NK-92MI ${ }^{\text {hCD16-GFP }}$ cells were significantly enhanced by dinutuximab. Finally, the release of perforin-granzyme B and the expression of CD107a in NK-92MI ${ }^{\text {hCD16-GFP }}$ cells stimulated by retinoblastoma cells were obviously increased by dinutuximab.

Conclusion: This study indicates that retinoblastoma impairs the integrity of the BRB and contributes to dysregulated immune cell infiltrates. GD2 is a specific target for natural killer (NK) cell-based immunotherapy and that the combination of dinutuximab and NK-92MI ${ }^{\text {hCD16-GFP }}$ cells exerts potent antitumor effects through antibody-dependent cell-mediated cytotoxicity.

Keywords: tumor immune microenvironment, natural killer cells, NK-92MI, GD2, antibody-dependent cell-mediated cytotoxicity

\section{Introduction}

Retinoblastoma is the most common pediatric ocular cancer that initiates in response to biallelic RB1 inactivation. ${ }^{1-3}$ Mortality rates vary from 3-5\% in developed countries to $70 \%$ in developing countries. ${ }^{2-4}$ Socioeconomic and cultural 
disparities lead to barriers to medical care, resulting in poorer patient survival in developing countries. ${ }^{2,3}$ Current chemotherapies have limited therapeutic effects for refractory diseases, including recurrent retinoblastoma, and extraocular dissemination into the central nervous system and bloodstream. ${ }^{5}$ Unlike most cancers that have frequent crosstalk with the vascular system, retinoblastoma is believed to be separated from the blood cells by the bloodretinal barrier (BRB), which stops the exchange of macromolecules between the retina and circulation. ${ }^{6,7}$

The search for new therapeutic targets has been the focus of retinoblastoma treatment. GD2 is a disialoganglioside that is highly expressed in some cancers including neuroblastoma, melanoma, osteosarcoma, lung cancer, and breast cancer. ${ }^{8}$ GD2 promotes cell proliferation, migration, stemness, and chemoresistance through MAPK, PI3K/Akt, and FAK/paxillin signaling cascades. $^{9-13}$ The rate-limiting enzyme of the GD2 production pathway is B4GALNT1. Both GD2 and B4GALNT1 have been reported as reliable markers of prognosis in certain cancers, such as melanoma and neuroblastoma. ${ }^{14,15}$ However, studies about GD2 in retinoblastoma are quite limited, and only few studies have reported the diagnostic and prognostic value of GD2 and B4GALNT1. ${ }^{14,16-19}$

Because GD2 is restricted to few normal tissues, GD2specific monoclonal antibodies have been tested in numerous clinical trials and proved to be safe and effective. ${ }^{20-25}$ The chimeric antibody dinutuximab has been shown to be effective in the maintenance therapy of children with highrisk neuroblastoma and has been used in combination with GM-CSF, IL-2 and isotretinoin for standard treatment of this stage. ${ }^{26}$ Dinutuximab exerts antitumor effects mainly through the induction of antibody-dependent cell-mediated cytotoxicity (ADCC). In this process, natural killer (NK) cells function through intrinsic cytolytic granules coated with CD107a, and stimulation of the tumor triggers degranulation and the subsequent release of perforin and granzymes. ${ }^{27}$ Encoded by FcyRIIIA, CD16 is the predominant $F c$ receptor $(F c \gamma R)$ on NK cells and is considered the most important inducer of degranulation. ${ }^{28,29}$ Given that NK cells are the major effector of ADCC, researchers are investigating adoptive NK cell therapy to further augment the efficacy of monoclonal antibodies or other methods to enhance the activities of host NK cells. ${ }^{30-35}$ Surprisingly, several NK cell lines, including NK-92MI, have been used in early-phase clinical trials for leukemia, renal cell carcinoma and metastatic melanoma, and some encouraging responses have been observed. ${ }^{36-38}$ However, CD16 is absent on the membrane of NK-92MI. ${ }^{39}$

The field of retinoblastoma-focused research is barren due to the low morbidity or the commonly accepted concept that the BRB blocks macromolecular drugs from entering ocular sites. ${ }^{40}$ The few published studies mainly focused on in vitro cell-mediated immunotherapy and did not determine the tumor-specific antigen. ${ }^{4-46}$ However, the concept of an absolute BRB has been challenged by an increasing numbers of studies. First, structural and functional deterioration of the BRB has been recorded in age-related diseases such as macular degeneration. ${ }^{6} \mathrm{Next}$, approximately $1 \%$ of nonocular tumors can metastasize to the inner retina through the retinal circulation without choroidal involvement. ${ }^{47,48}$ Moreover, macromolecules were observed to cross the BRB, as evidenced by retinaspecific $\mathrm{T}$ cells/antibodies in the circulation in experimental or spontaneous uveoretinitis. ${ }^{49,50}$ Finally, successful antitumor treatment with intravenous-administered monoclonal antibodies has also been reported in cases of metastatic ocular lymphoma and melanoma. ${ }^{51,52}$ In this study, we first examined GD2 expression and the immune cell profile of retinoblastoma and then investigate the antiretinoblastoma effects of dinutuximab and CD16-expressing NK-92MI cells.

\section{Materials and Methods Cell Lines}

We purchased the NK cell line NK-92MI, the retinal pigment epithelial cell line ARPE-19, and the retinoblastoma cell lines Y79 and WERI-Rb-1 from the American Type Culture Collection. All cells were cultured at $37{ }^{\circ} \mathrm{C}$ in a $5 \% \mathrm{CO}_{2}$ incubator. Trypan blue staining identified the activity of cells, and only highly viable cells (more than $95 \%$ ) were used in this experiment. The medium used for the culture of NK-92MI cells was $\alpha$-Minimum Essential Medium, and $2 \mathrm{mM}$ L-glutamine, $0.2 \mathrm{mM}$ inositol, 0.02 $\mathrm{mM}$ folic acid, $0.1 \mathrm{mM}$ 2-mercaptoethanol, 12.5\% FBS and $12.5 \%$ horse serum were added. ARPE-19, Y79, and WERI-Rb-1 cells were cultured with RPMI 1640 medium containing 10\% FBS. Primary retinoblastoma cell lines $\mathrm{RBJY}$ and SNPH-Rb-C24 were established as described in our previous work and conducted under the policies of the Scientific Ethics Committee of Shanghai Jiao Tong University, and the guardians of the patients provided written informed consent. ${ }^{53}$ The phenotype (Figure S1A), similar immunostaining patterns of CD56 and 
synaptophysin (Figure S1B and $\underline{\mathrm{C}}$ ), and identical short tandem repeat profiles (Supplementary excel) between the original tumor cells and RBJY cells confirmed the origination of RBJY cells from the original tumor. Primary cells were also maintained in RPMI-1640 medium with the addition of $1 \%$ penicillin-streptomycin. All cellrelated reagents were purchased from Gibco (USA).

\section{Lentivirus Production and Infection}

The plasmid pGMLV-CMV-CD16-EF1-GFP-T2A-Puro was purchased from Shanghai Genomeditech Company, and then the sequence was verified by Sanger sequencing. GFP was inserted as a fluorescent marker to determine the infection efficiency and for gating in the flow cytometric analysis. The puromycin-resistant gene was the selective marker of this vector for the selection and enrichment of GFP-positive clones. The lentivirus was generated by cotransfecting $80 \%$ confluent HEK293T cells with psPAX2 and pMD2G using Lipofectamine 3000 (Invitrogen). The QuickTiter Lentivirus Quantitation Kit (Cell Biolabs, Inc.) was used to detect the virus titer according to a previous reference. ${ }^{54}$

A total of $3 \times 10^{5}$ NK-92MI cells were seeded into a 48 -well plate in a final volume of $100 \mu \mathrm{L}$, and then lentivirus was added at a multiplicity of infection of 500. At the same time, polybrene was also added to a final concentration of $10 \mu \mathrm{g} / \mathrm{mL}$. Twentyfour hours later, the virus solution was replaced by the fresh complete culture medium. After an additional 24 hours, puromycin at a final concentration of $2 \mu \mathrm{g} / \mathrm{mL}$ was supplemented for continuous selection. After 7 days of selection, the cells were subject to flow cytometry (FC) to determine the infection efficiency.

\section{FC}

Cells were stained with anti-GD2 (Cat\# 68456, Abcam, 1:100), anti-CD16-Brilliant Violet 510 (Cat\# 302047, Biolegend, 1:100), anti-CD16-APC (Cat\# 302011, Biolegend, 1:100), anti-CD107a-PerCP/Cy5.5 (Cat\# 328615, Biolegend, 1:100), goat anti-mouse IgG-Alexa Fluor 488 (Cat\# 150117, Abcam, 1:4000), and goat antimouse IgG-Alexa Fluor 647 (Cat\# 150115, Abcam, 1:4000). ${ }^{12,55-57}$ The apoptosis and death of retinoblastoma cell lines were determined using an apoptosis detection kit (Cat\# 640932, Biolegend). The instrument involved in the FC assays was the BD LSRFortessa X-20, and the software used for data analysis was FlowJo.

\section{Fluorescence-Activated Cell Sorting (FACS)}

After puromycin selection, NK-92MI cells infected with CD16 were filtered through $40 \mu \mathrm{m}$ cell strainers. Cells were then stained with anti-CD16-APC (Cat\# 302011, Biolegend) in $1 \mathrm{~mL}$ of PBS-BSA at $4{ }^{\circ} \mathrm{C}$ for 15 minutes in the dark, washed once with PBS-BSA, resuspended in $2 \mathrm{~mL}$ of $\alpha$-MEM, and sorted using a FACSAria II flow cytometric cell sorter by an experienced operator. The sorted subpopulation was named NK-92MI ${ }^{\text {hCD16-GFP }}$ and was concentrated by centrifugation and resuspended in complete $\alpha$-MEM.

\section{ADCC \\ LDH Release Assay}

A CytoTox 96 Non-Radioactive Cytotoxicity Assay (Promega) was used to determine the amount of released LDH following the instructions of the kit. A constant number of retinoblastoma cells $\left(1 \times 10^{4}\right.$ cells in $\left.50 \mu \mathrm{L}\right)$ were seeded into a 96 -well $\mathrm{U}$ bottom plate and incubated with dinutuximab (Creative Biolab) or an isotype control at a final concentration of $1 \mu \mathrm{g} / \mathrm{mL}$ for half an hour at $37{ }^{\circ} \mathrm{C}$. Then, $50 \mu \mathrm{L}$ of NK-92MI ${ }^{\text {hCD16-GFP }}$ cells were added for coculture for 6 hours, and the ratio of NK-92MI ${ }^{\mathrm{hCD} 16-\mathrm{GFP}}$ cells to tumor cells was 1:1, 5:1, and 10:1. The supernatants were collected, and the amount of released LDH was recorded by a colorimetric reaction. Moreover, spontaneous LDH release from NK-92MI ${ }^{\mathrm{hCD} 16-\mathrm{GFP}}$ cells and tumor cells as well as maximum LDH release from tumor cells were simultaneously measured. The specific lysis rate of tumor cells was indicated in the instructions.

\section{Apoptosis Assay}

Retinoblastoma cells were labeled with CM-Dil (Life Technologies) 24 hours in advance. A total number of $2 \times 10^{4}$ retinoblastoma cells were incubated in a 96-well U bottom plate with $1 \mu \mathrm{g} / \mathrm{mL}$ dinutuximab or the isotype control for 0.5 hours and then cocultured with NK92 $\mathrm{MI}^{\mathrm{hCD} 16-\mathrm{GFP}}$ cells at $\mathrm{E} / \mathrm{T}$ ratios of $1: 1,5: 1$ and $10: 1$ in a $5 \% \mathrm{CO}_{2}$ atmosphere at $37{ }^{\circ} \mathrm{C}$ for an additional 6 hours. Both GFP fluorescence and the cell tracker CM-Dil were applied to distinguish NK-92MI ${ }^{\text {hCD16-GFP }}$ cells from retinoblastoma cells. The dead and apoptotic target cells were detected excluding the annexin $\mathrm{V}^{-} / 7-\mathrm{AAD}^{-}$population in GFP-negative as well as CM-Dil-positive gated cells. The instrument involved in the apoptosis assay was a Beckman CytoFLEX flow cytometer, and the software used for data analysis was CytExpert. 


\section{Cytotoxicity Assay of NK-92MI ${ }^{\text {hCDI6-GFP }}$ Cells}

\section{Enzyme-Linked Immunosorbent Assay (ELISA)}

An ELISA was performed to analyze the effect of dinutuximab on the ability of NK-92MI ${ }^{\text {hCD16-GFP }}$ cells to produce perforin and granzyme $\mathrm{B}$ under stimulation with retinoblastoma cells. Then, $5 \times 10^{4}$ retinoblastoma cells were preincubated for 0.5 hours with dinutuximab or the isotype control in advance, and cocultured with $5 \times 10^{5} \mathrm{NK}-92 \mathrm{MI}^{\mathrm{hCD} 16-\mathrm{GFP}}$ for an additional 6 hours. Supernatants were collected, and perforin and granzyme B were detected using a human perforin ELISA kit (Invitrogen) and a human granzyme B ELISA kit (Invitrogen) following the manufacturer's instructions.

\section{CDI07a Assay}

Different retinoblastoma cells $\left(5 \times 10^{4}\right)$ were pretreated with $1 \mu \mathrm{g} / \mathrm{mL}$ dinutuximab or the isotype control 0.5 hours before coincubation with the same number of NK-92MI ${ }^{\text {hCD16-GFP }}$ cells in a 96-well U plate. After pretreatment with dinutuximab, incubation was continued for 3 hours with the addition of $1 \mu \mathrm{L}$ of anti-CD107a-PerCP/Cy5.5 or the isotype control. Then, monensin (Biosciences) was supplemented at a final concentration of $6 \mu \mathrm{g} / \mathrm{mL}$, and then coculture was continued for an additional 3 hours at $37^{\circ} \mathrm{C}$. Last, CD107a expression in NK-92MI ${ }^{\text {hCD16-GFP }}$ cells was determined by a BD LSRFortessa X-20 flow cytometer using GFP as a gating signal, and FlowJo software was adopted to analyze the data.

\section{Gene Set Enrichment Analysis (GSEA)}

Our previous RNA-sequencing data of 3 pairs of matched retinoblastoma and retina tissues were used to further understand the gene set that might be involved. ${ }^{58}$ The data were deposited into the Gene Expression Omnibus under accession number GSE111168. The data were downloaded, normalized and $\log 2$ transformed, and then retina samples were grouped as "normal", and retinoblastoma samples were grouped as "tumor". The datasets were then analyzed using GSEA. ${ }^{59}$ Signal-to-noise and 1000 permutations of the genes were applied to the GSEA with the gene sets obtained from the Molecular Signatures Database v6.2 for all hallmarks and with the gene sets obtained from the Gene Ontology (GO) analysis of biological processes related to the immune system, including gene sets related to cytokines, the innate immune response or NK cells.

\section{Immunohistochemistry}

The medical records of patients who were pathologically diagnosed with retinoblastoma and underwent enucleation at Shanghai Ninth People's Hospital between January 2014 and December 2018 were retrieved and analyzed. The American Joint Committee on Cancer staging was used to stage the retinoblastoma rather than the International Intraocular Retinoblastoma Classification (IIRC) because of some missing information on the IIRC stage. After excluding the samples with large necrotic areas (more than 90\%), fifty-four patients' samples were included. Thirteen normal retina samples were retrieved from corneal donor eyes. This study was approved by and conducted following the policies of the Scientific Ethics Committee of Shanghai Jiao Tong University, and all the patients or guardians provided written informed consent.

The deparaffinized tissue sections were boiled in 10 $\mathrm{mM}$ sodium citrate buffer for 15 minutes and then allowed to cool at room temperature for 0.5 hours. Specimens were incubated with mouse anti-human GD2 (Abcam, 1:500), rabbit anti-human CD3 (Abcam, 1:100), rabbit anti-human CD20 (Abcam, 1:100) and rabbit anti-human granzyme B (Abcam, 1:100) at $4{ }^{\circ} \mathrm{C}$ for 16 hours, washed with PBS and stained with an anti-mouse/rabbit secondary antibody (Cell Signaling Technology) for 60 minutes at room temperature. A DAB kit (Vector, USA) was used for immunohistochemical staining following the manufacturer's instructions. After counterstaining the nuclei with hematoxylin, slides were observed using light microscopy.

Due to the heterogeneity of immunohistochemical staining, we introduced the immunoreactive score (IRS) to comprehensively evaluate the positive rate and staining intensity of pathological specimens (Table 1). The final result of the IRS evaluation system is that each sample can obtain an IRS score between 0 and 12. Two independent pathologists evaluated and scored GD2-stained samples and used k-tests to assess differences between them. When there was a significant difference, a third pathologist re-evaluated the controversial samples and discussed with them to reach a consensus.

Table I The Immunoreactive Score (IRS) Used to Estimate the Immunoreaction of GD2

\begin{tabular}{|l|l|l|}
\hline Points & Intensity of Staining & Percentage Positive Cells \\
\hline 0 & No staining & 0 \\
1 & Weak & $<20$ \\
2 & Moderate & $20-50$ \\
3 & Strong & $50-80$ \\
4 & - & $>80$ \\
\hline
\end{tabular}

Note: The product of staining intensity and the percentage of stained cells results in a score of $0-12$. 


\section{Vitreous Cytology}

Due to the low percentage of immune cells in retinoblastoma masses, vitreous cytopathology was used to enrich and detect trace amounts of cellular components. Fresh vitreous bodies without clinically confirmed vitreous hemorrhage were collected from retinoblastoma patients who underwent therapeutic enucleation at Shanghai Ninth People's Hospital following the policies of the Scientific Ethics Committee of Shanghai Jiao Tong University. All patients' guardians provided written informed consent. After enucleation, eyes were rinsed with saline, and then carefully opened using a sterile scalpel to avoid blood contamination. Vitreous bodies were collected by needle aspiration and transferred in complete RPMI-1640 culture medium to avoid cell lysis. Within 24 hours, cytospins were prepared using a Cytospin Cytocentrifuge (Thermo Fisher Scientific) and a Cytospin Starter kit (Thermo Fisher Scientific) following user manuals. May-Grünwald-Giemsa (MGG) or Wright's stain was performed on cytospins of all cases. Samples with abundant erythrocytes indicating vitreous hemorrhage and/or blood contamination were excluded from further immunocytochemistry analyses. The remaining vitreous samples after immunocytochemistry were embedded in paraffin for immunohistochemistry.

\section{Immunocytochemistry}

First, cytospins were fixed using $4 \%$ paraformaldehyde in PBS (pH 7.4) for 10 minutes at room temperature and then washed three times with ice-cold PBS. Then, the cytospins were subjected to antigen retrieval buffer (100 mM Tris, 5\% urea, $\mathrm{pH} 9.5$ ) at $95^{\circ} \mathrm{C}$ for 10 minutes followed by a wash with PBS. Next, the cytospins for granzyme B staining were permeabilized for 10 minutes with PBS containing $0.5 \%$ saponin (Sigma).Then, the samples were blocked with $1 \%$ BSA and $22.52 \mathrm{mg} / \mathrm{mL}$ glycine in PBST for 30 minutes at room temperature and subsequently incubated with primary antibodies for $\mathrm{CD} 3, \mathrm{CD} 20$ and granzyme $\mathrm{B}$ in a humidified chamber overnight at $4{ }^{\circ} \mathrm{C}$. Finally, cytospins were incubated with the secondary antibody in 1\% BSA for 1 hour at room temperature in the dark and subsequent $1 \mu \mathrm{g} / \mathrm{mL}$ DAPI (Sigma) staining. One pathologist with experience in ocular cytology reviewed all the slides.

\section{Quantification and Statistical Analysis}

Statistical methods are listed in the methods, text or figure legends. Statistical quantification was performed using GraphPad Prism 7.0. Student's $t$-test was the generally used method unless otherwise stated in the figure legends or text. The error bars in the experiment represent the standard deviation (SD) or standard error (SE) of three or more independent experiments.

\section{Results \\ GD2 Synthase and GD2 are Highly Expressed in Retinoblastoma}

Our published RNA-sequencing data revealed 15-fold higher expression of the GD2 synthase encoding gene B4GALNT1 in retinoblastoma specimens than in normal retina specimens (Figure S2A and B). Furthermore, FC results showed that GD2-positive cells accounted for over $90 \%$ of Y79 and WERIRb- 1 cells, more than $40 \%$ of RBJY cells, and $76 \%$ of SHNP$\mathrm{Rb}-\mathrm{C} 24$ cells, while the normal retinal pigmented epithelium ARPE-19 was GD2 negative (Figure 1B). The immunohistochemical analysis revealed heterogeneous GD2 expression in retinoblastomas and negative expression in normal retinas (Figure 1A). Further analysis of the immunohistochemical results showed that $63 \%$ of retinoblastoma tissues were negatively stained for GD2, $18 \%$ exhibited an IRS between $1-4,6 \%$ exhibited an IRS between 5-8, and the remaining 13\% exhibited an IRS ranging from 9-12 (data not shown). Taken together, our data indicate that B4GALNT1 is highly expressed in retinoblastomas than in normal retinas, and GD2 shows a heterogeneously high expression profile in both retinoblastoma tissues and cell lines compared to normal controls.

\section{GD2 Expression Indicates an Advanced Stage and the Active Proliferation of Retinoblastoma}

The clinicopathologic information of patients diagnosed with retinoblastoma is summarized in Table 2. The GD2positive rate based on age, sex, and TNM stage was statistically nonsignificant. Further investigation of the IRS and TNM stage among the GD2-positive group was performed, and the sample staged as T2N1M0 was excluded because of the small patient number (only one patient). The results showed that the average IRS was higher in the advanced retinoblastoma group than in the nonadvanced retinoblastoma group (T4N0M0, IRS 9.2; T3N0M0, IRS 6.5 ; T2N0M0, IRS 2.8 ; $\mathrm{p}=0.0183$ by oneway ANOVA) (Figure 1C), which indicated a positive correlation between strong GD2 staining and an advanced stage of retinoblastoma. We next discovered a significant difference in the positive rate of GD2 staining between different Ki67 groups (Table 2). Further analysis of the 
A

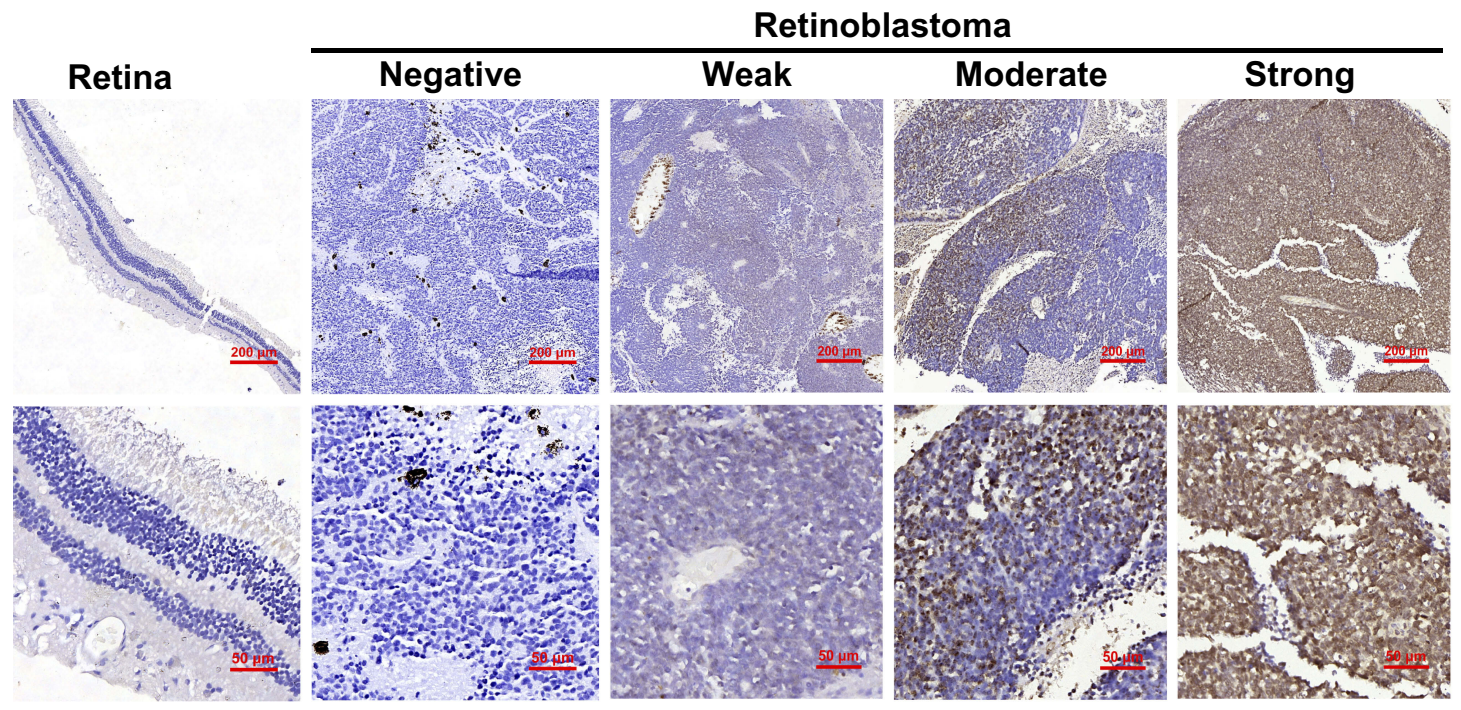

B

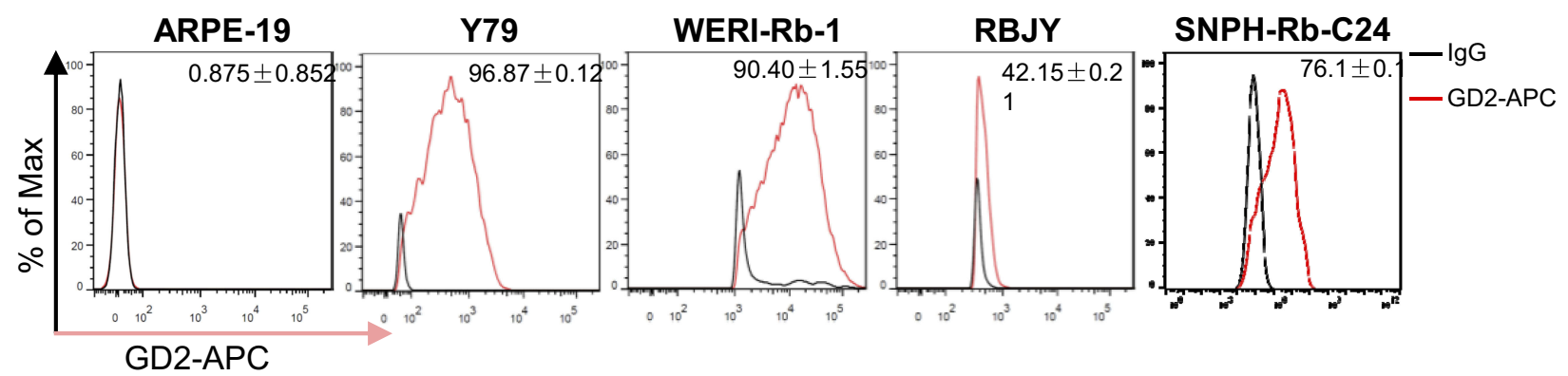

C

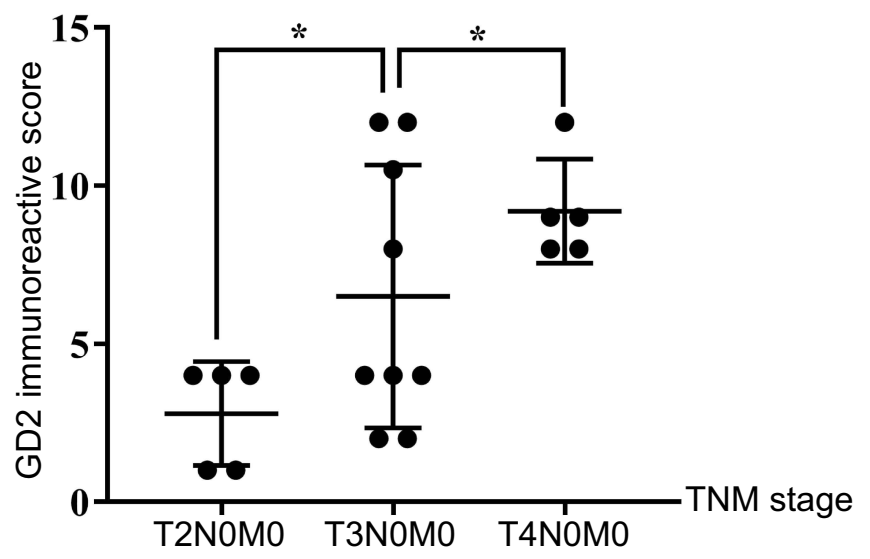

D

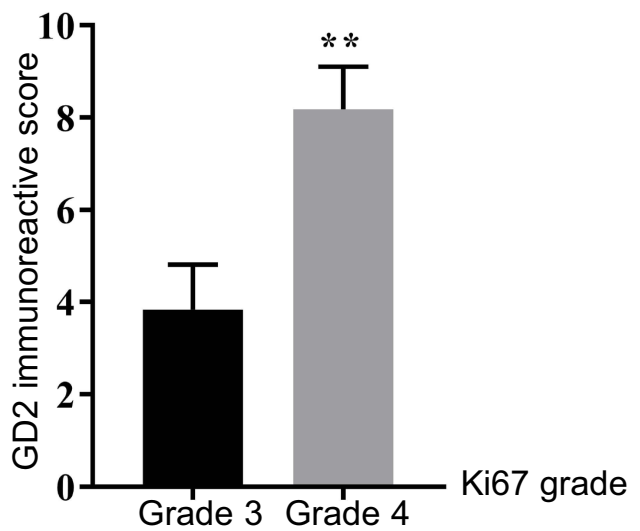

Figure I GD2 is highly expressed in retinoblastoma and is related to an advanced stage and fast proliferation. (A) Representative images of heterogeneous GD2 staining in retinoblastoma tissues $(n=54)$. The staining intensity was classified as negative, weak, moderate or strong by two experienced pathologists. Normal retina tissues $(n=13$ ) were stained as a negative control. (B) The percentage of GD2-positive cells was estimated by FC in the normal control cell line ARPE-19, two retinoblastoma cell lines Y79 and WERI-Rb-I, and two primary retinoblastoma cultures RBJY and SNPH-Rb-C24. Numerical values denote the mean \pm SD. (C) The correlation of the GD2 IRS with TNM stage in GD2-positive retinoblastoma species. The sample from TxNIM0/TxNOMI was excluded due to the small population ( $\mathrm{n}=\mathrm{I}$ ). Numerical values denote the mean \pm SD. ${ }^{*} p<0.05$ by one-way ANOVA. (D) The average GD2 IRS between the grade 3 and grade 4 Ki67 groups. Numerical values denote the mean \pm SD. ** $<0.0$ I by Student's t-test. 
Table 2 Correlation of GD2 Expression and the Clinicopathologic Factors of Chinese Retinoblastoma Patients

\begin{tabular}{|c|c|c|c|}
\hline $\begin{array}{l}\text { Clinic Pathologic } \\
\text { Feature }\end{array}$ & $\begin{array}{l}\text { GD2+ } \\
\text { (\%) }\end{array}$ & $\begin{array}{l}\text { GD2- } \\
\text { (\%) }\end{array}$ & P value* \\
\hline $\begin{array}{l}\text { Age (Year) } \\
\qquad \text { Median (min, max) }\end{array}$ & $4(I, 28)$ & $3(1,74)$ & 0.5907 \\
\hline $\begin{array}{l}\text { Sex n (\%) } \\
\text { Male } \\
\text { Female }\end{array}$ & $\begin{array}{l}12(60) \\
8(40)\end{array}$ & $\begin{array}{l}22(64.7) \\
12(35.3)\end{array}$ & 0.7762 \\
\hline $\begin{array}{l}\text { TNM Stage } n(\%) \\
\text { TINOM0 (I) } \\
\text { T2NOM0 (I0) } \\
\text { T3NOM0 (27) } \\
\text { T4NOM0 (I4) } \\
\text { TxNIM0/TxNOMI (2) }\end{array}$ & $\begin{array}{l}0(0) \\
5(25) \\
9(45) \\
5(25) \\
I(5)\end{array}$ & $\begin{array}{l}\text { I (2.9) } \\
5(14.7) \\
\text { I8 (53.0) } \\
9(26.5) \\
\text { I (2.9) }\end{array}$ & 0.870 \\
\hline $\begin{array}{l}\text { Ki67 Gradef n (\%) } \\
\qquad \begin{array}{l}\text { I (8) } \\
2(9) \\
3(17) \\
4(20)\end{array}\end{array}$ & $\begin{array}{l}0(0) \\
1(5) \\
6(30) \\
13(65)\end{array}$ & $\begin{array}{l}8(23.5) \\
8(23.5) \\
11(32.4) \\
7(20.6)\end{array}$ & 0.0021 \\
\hline $\begin{array}{l}\text { Recurrence n (\%) } \\
\text { Yes } \\
\text { No }\end{array}$ & $\begin{array}{l}2(10) \\
18(90)\end{array}$ & $\begin{array}{l}3(8.8) \\
31(9 \mid .2)\end{array}$ & $>0.9999$ \\
\hline $\begin{array}{l}\text { Metastasis n (\%) } \\
\text { Yes } \\
\text { No }\end{array}$ & $\begin{array}{l}1(5) \\
19(95)\end{array}$ & $\begin{array}{l}3(8.8) \\
31(91.2)\end{array}$ & $>0.9999$ \\
\hline
\end{tabular}

Notes: *An unpaired t-test with Welch's correction was used to evaluate age. Fisher's exact tests were used to evaluate sex, TNM stage, Ki67 grade, recurrence, and metastasis. ${ }^{\dagger}$ Percentage of Ki67: staining between 0-20\%, 20-50\%, 50-80\%, $80-100 \%$ was given a score of I, 2, 3 and 4, respectively.

GD2 IRS between the grade 4 and grade 3 groups implied that the GD2 IRS had a positive correlation with Ki67 staining ( $8.18 \pm 0.93$ vs $3.83 \pm 0.98 ; \mathrm{p}=0.0062$, Student's $t$-test) (Figure 1D). Finally, we aimed to determine whether GD2 has prognostic value for recurrence. Three of 5 patients with recurrence exhibited negative staining for GD2 (Table 2), and the remaining obtained an IRS of 2 and 8 . However, we could not draw any conclusion due to the small population of individuals with recurrence; the same was true for metastasis. Thus, our findings suggest that GD2 expression is positively correlated with retinoblastoma stage and proliferation.

\section{The Immune Microenvironment is Deregulated in Retinoblastoma Patients}

Our previous RNA-sequencing data of 3 pairs of matched retinoblastoma and retina tissues were subjected to GSEA based on 50 hallmark gene sets to investigate the tumor immune microenvironment (TIME) of retinoblastoma. GSEA showed that 28 gene sets were significantly upregulated in tumors, and the most enriched were the complement, inflammatory response and IL6/JAK/STAT3 pathways (Figure 2A). To identify cellular processes related to the immune response, we further conducted GSEA with gene sets for GO terms related to cytokines, the innate immune response and NK cell-mediated immunity. Our analysis revealed that the pathways involved in the biosynthesis and secretion of cytokines, innate immune were all deregulated in retinoblastoma (Figure S3A and B). Finally, the genes closely related to NK cell immune modulation were also deregulated in the TIME of retinoblastoma (Figure 2B and C). The expression of stimulatory natural cytotoxicity receptors, such as NCR3, NCR1, KLRK1, and KLRC4 (mostly known as NKp30, NKp46, NKG2D, and NKG2F), and molecules involved in the perforin-granzyme cytolytic pathway, such as LAMP1 (commonly known as CD107a) and SERPINB9, were all deregulated in the devastating tumor cell microenvironment (Figure 2C). Collectively, these results indicate that the ocular immune microenvironment is deregulated in retinoblastoma patients.

\section{The BRB Is Disrupted by Retinoblastoma}

To reveal the underlying mechanism of the deregulated TIME and evaluate the possibility of intravenous drug administration in vivo, an immunohistochemical analysis of immune cells was conducted in retinoblastoma samples. The results showed the presence of $\mathrm{T}$ and $\mathrm{B}$ cells (Figure 3A and B); however, granzyme B-positive NK cells were not detected in all tissue sections, probably due to the low percentage of NK cells or the small proportion of stromal components in retinoblastoma masses. As expected, no immune cells were observed in normal retina tissues (Figure 3C and D). Inspired by the fact that vitreous cytopathology can easily detect trace amounts of cellular components, cytospins of the vitreous body were made to concentrate and observe tumor-associated immune cells. ${ }^{60,61}$ Lymphocytes mixed with tumor cells were observed on Giemsa slides (Figure 3E). Then, the immunocytochemical analysis revealed the existence of tumor-infiltrating immune cells evidenced by CD3positive $\mathrm{T}$ cells (Figure 3F). The immunohistochemical analysis further revealed CD20-positive B cells and granzyme B-positive NK cells (Figure $3 \mathrm{G}$ and $\mathrm{H}$ ). As expected, no immune cells except for the degenerative 

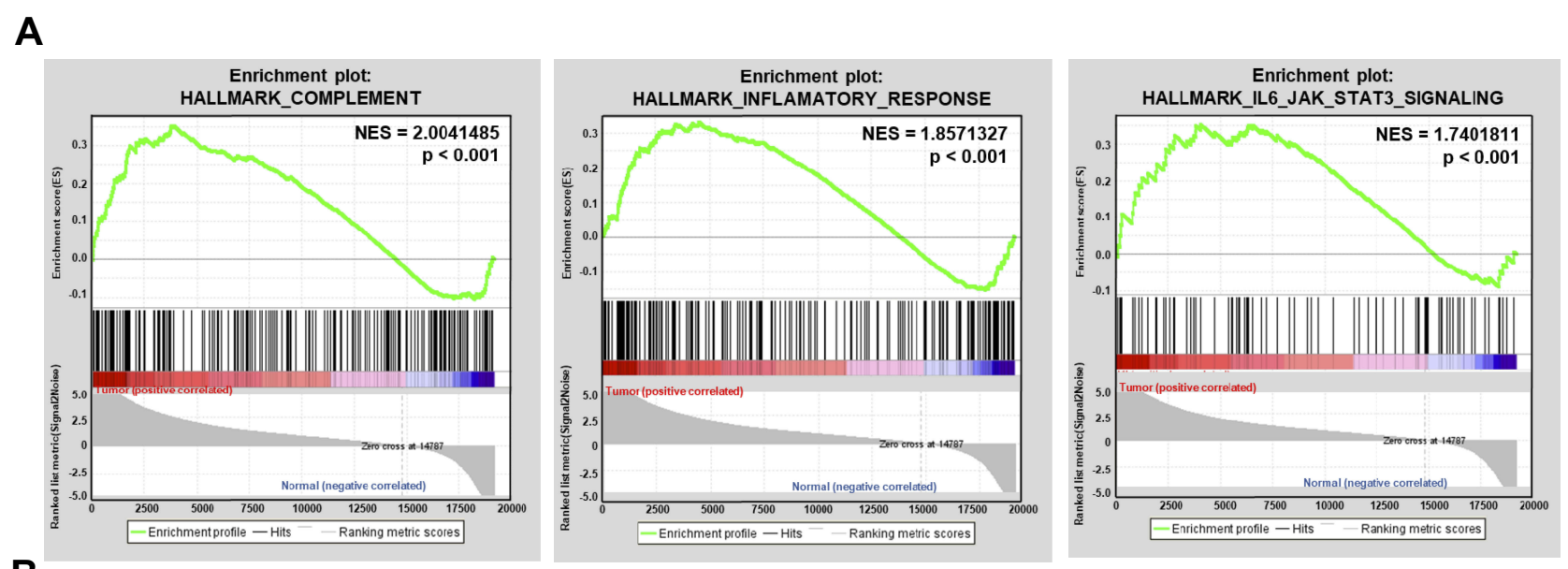

B
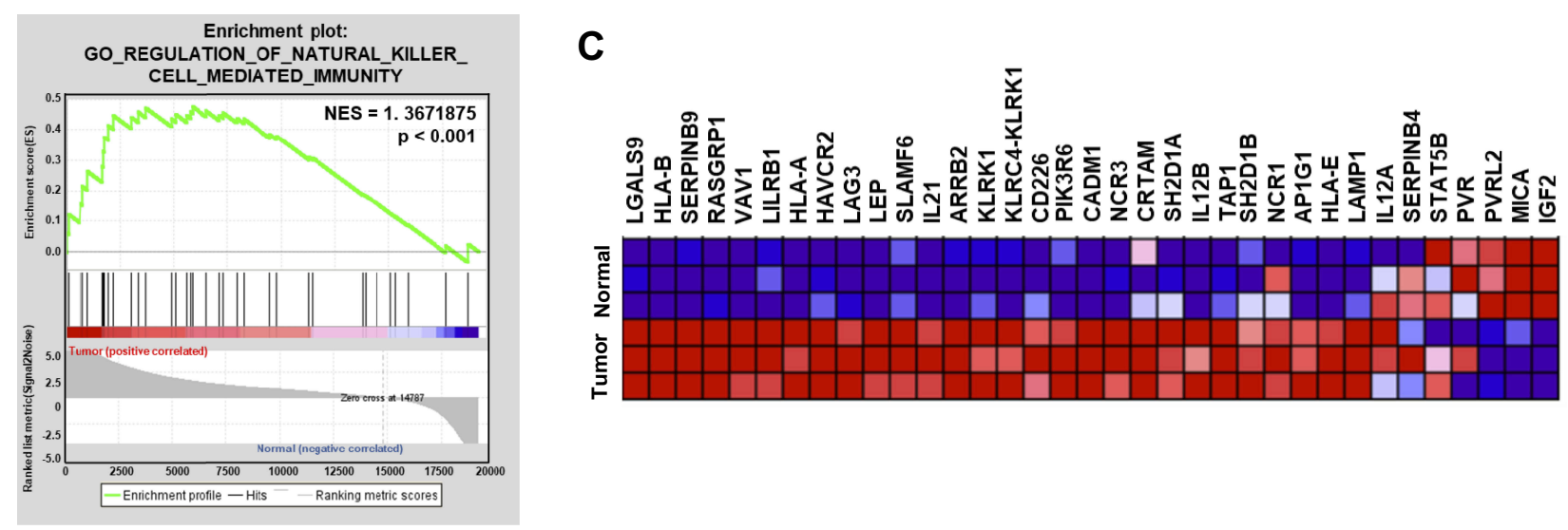

Figure 2 The immune response of the ocular microenvironment is deregulated. (A) GSEA enrichment plots demonstrate significant enrichment of the complement, inflammatory response and IL6/JAK/STAT3 gene sets in retinoblastoma versus retina samples. The normalized enrichment score (NES) and P value are listed on the enrichment plot. (B) GSEA enrichment plots demonstrate the deregulated NK cell-mediated immunity gene sets in retinoblastoma versus retina samples. The NES and $P$ value are listed on the enrichment plot. (C) Heat map of genes enriched in NK cell-mediated immunity.

retinal epithelium were detected in normal vitreous samples (Figure 3I). Collectively, our immunostaining data of immune cells on both tumor masses and tumor-infiltrating vitreous samples suggest the disruption of the BRB and consequent change in the TIME.

\section{Generation and Characterization of NK-92MI ${ }^{\text {hCD I6-GFP }}$ Cells}

Following the repeated puromycin selection of NK-92MI cells infected with human CD16, almost all cells were GFP positive (Figure 4A and B); however, the CD16positive subpopulation accounted for only $25 \%$ of the GFP-gated population (Figure S4), probably due to the hyposensitivity of the antibody or unsuccessful membrane expression. Then, FACS was conducted to sort the subpopulation with strong CD16 expression on the membrane. Ultimately, the percentage of CD16-expressing cells was almost 100\% (Figure 4B).

\section{Dinutuximab Enhances the ADCC of NK-92MI ${ }^{\text {hCDI6-GFP }}$ Cells Against}

\section{Retinoblastoma Cells}

The cytotoxicity of NK-92MI ${ }^{\text {hCD16-GFP }}$ cells against retinoblastoma cells in the presence or absence of dinutuximab was detected by LDH release assays and FC analysis. The LDH release assays showed significantly enhanced cytotoxicity of NK-92MI ${ }^{\text {hCD16-GFP }}$ cells against Y79 and WERI-Rb-1 cells in the presence of dinutuximab at different E:T ratios (Figure $4 \mathrm{C}$ and D). The primary retinoblastoma culture SNPH-Rb-C24 also showed a moderate response to NK-92MI ${ }^{\text {hCD16-GFP }}$ cells, which was further improved by dinutuximab (Figure 4F). RBJY cells were the least sensitive to gene-modified NK92MI cells, even in the presence of dinutuximab (Figure 4E).

An apoptosis analysis was conducted to confirm the results of the $\mathrm{LDH}$ release assays. The CM-Dil-labeled retinoblastoma cells were cocultured with NK92MI ${ }^{\text {hCD16-GFP }}$ cells at different E:T ratios (Figure 5A, 

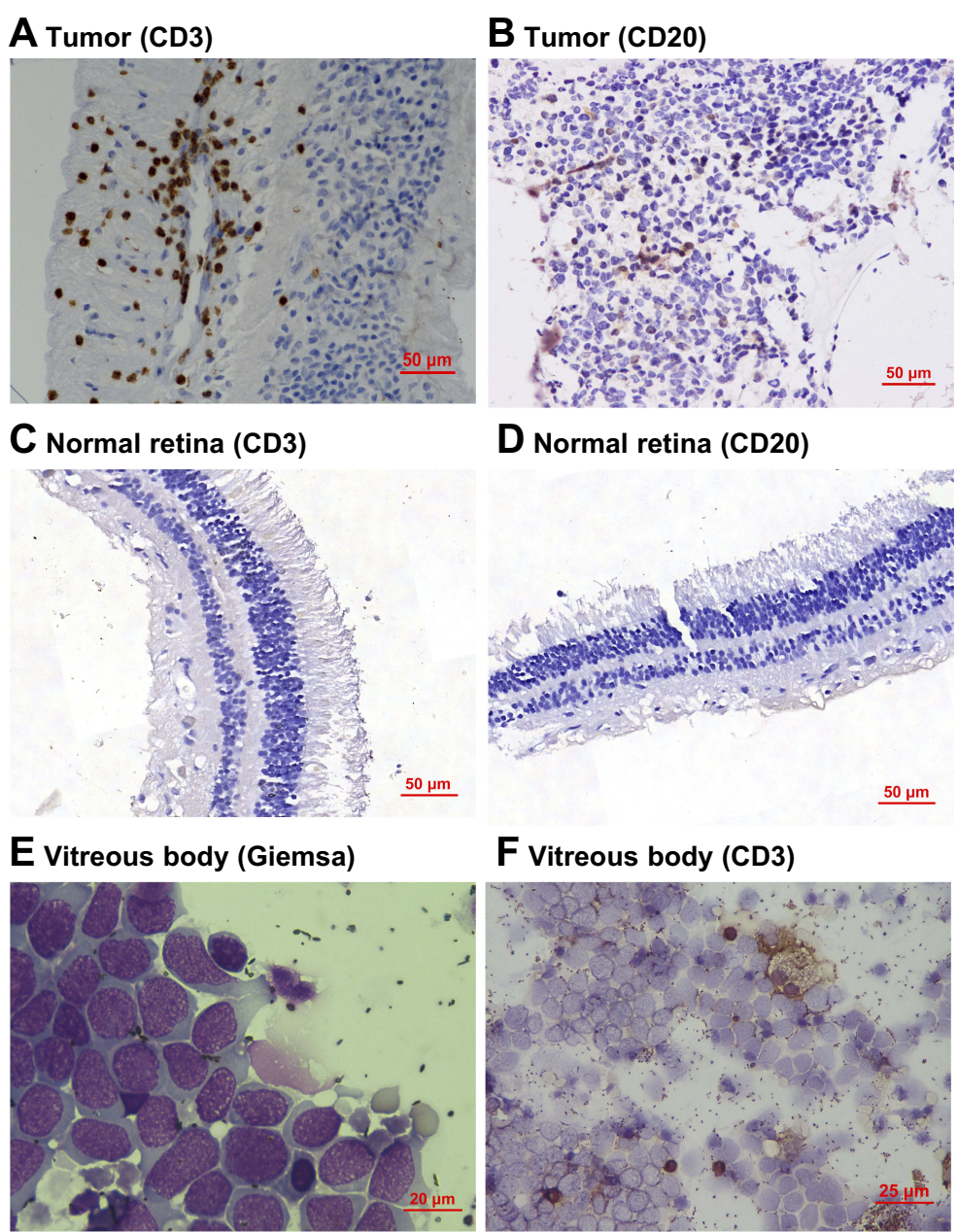

F Vitreous body (CD3)
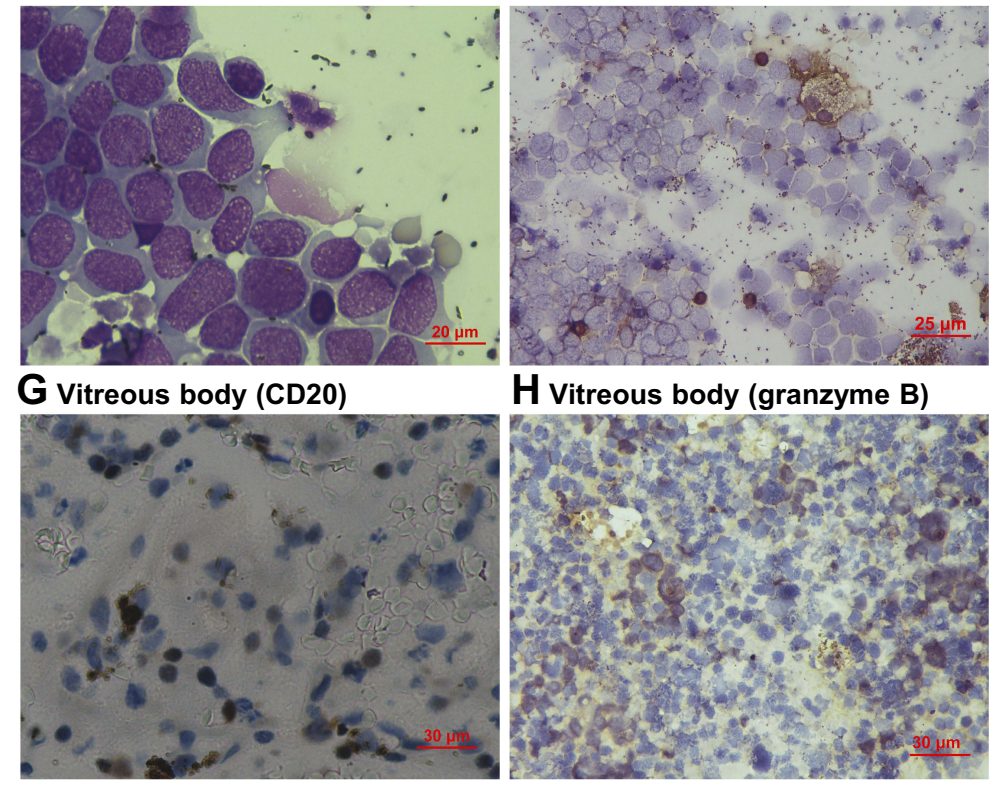

\section{H Vitreous body (granzyme B)}

I Normal vitreous body (Wright)
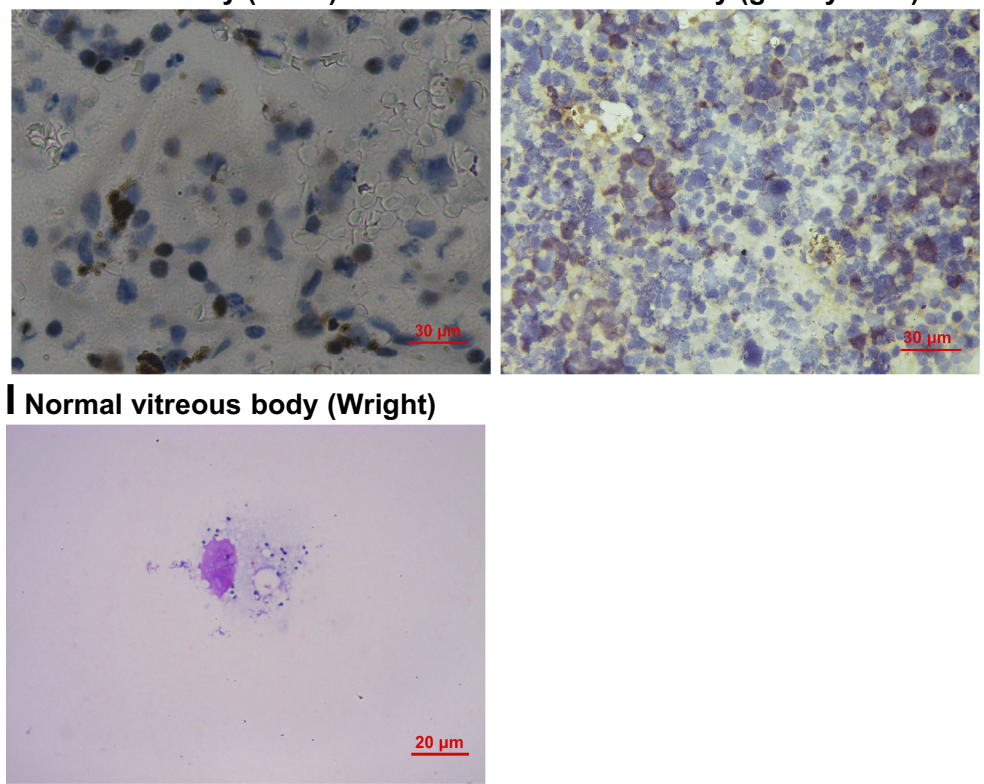

Figure 3 The blood-retinal barrier is disrupted by retinoblastoma. (A-D) Representative immunohistochemical images of CD3 and CD20 in retinoblastoma and normal retina tissues. (E-I) Representative images of vitreous bodies from retinoblastoma patients without vitreous hemorrhage. The images of Giemsa staining (E), CD3 staining $(\mathbf{F})$, CD20 staining $(\mathbf{G})$, granzyme B staining $(\mathbf{H})$, and the normal vitreous control (I) were taken at different magnifications as indicated. 
A
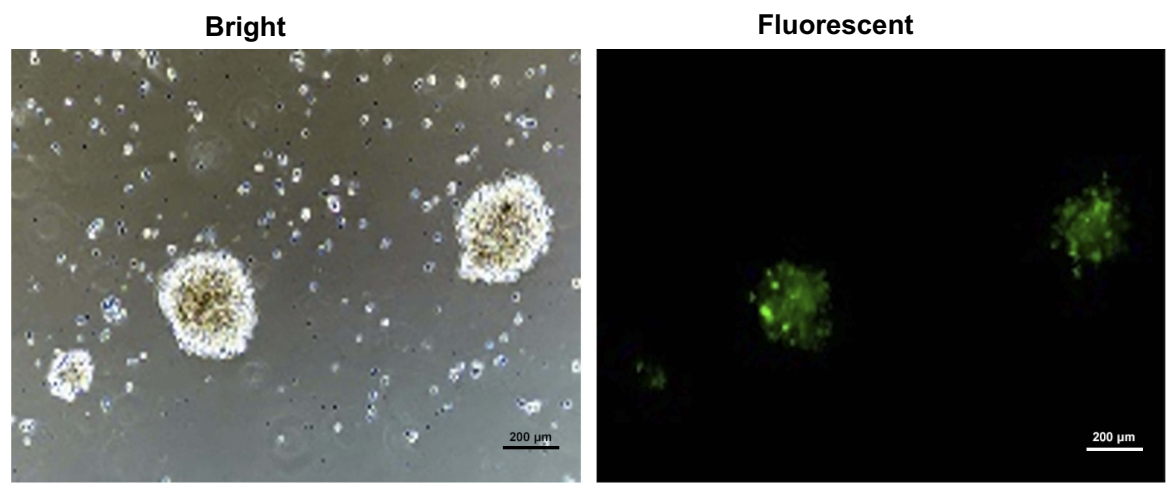

B
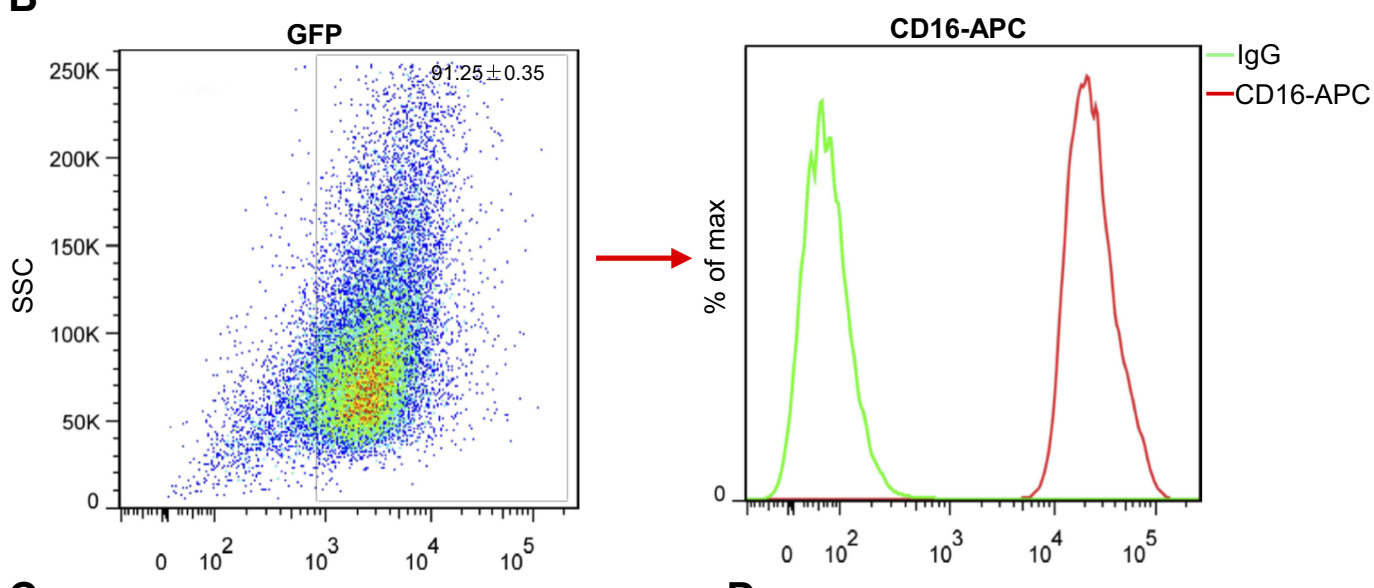

C

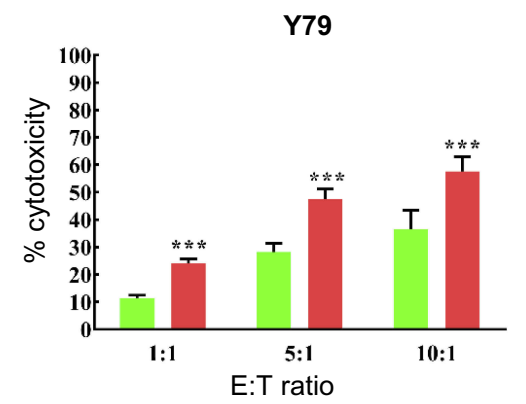

D

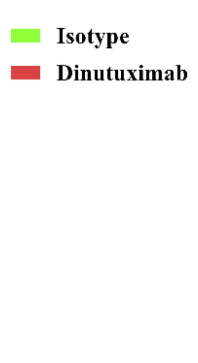

E

RBJY

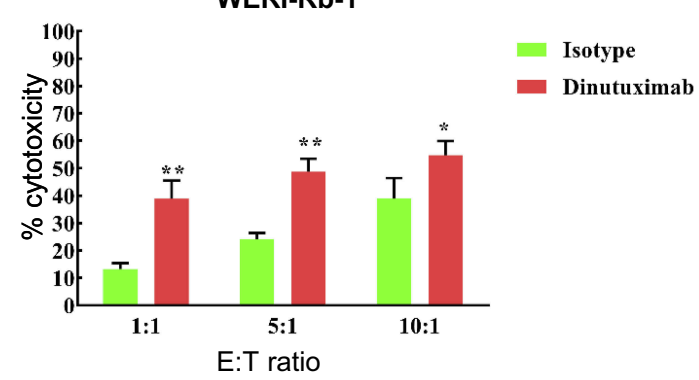

F
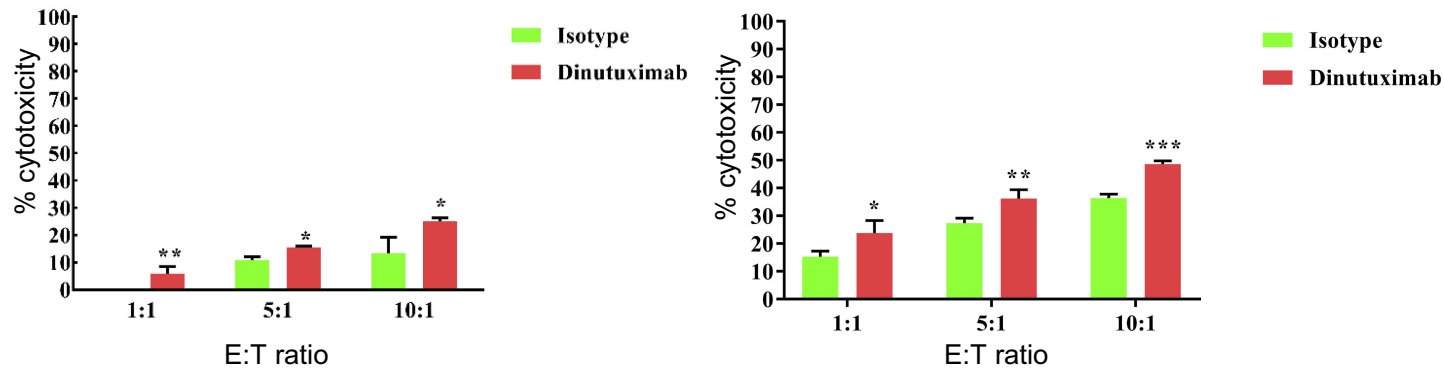

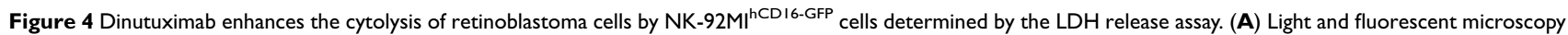
images of NK-92MI ${ }^{\text {hCDI6-GFP }}$ cells. (B) The percentage of GFP-positive NK-92MI ${ }^{\text {hCDI6-GFP }}$ cells and membrane CDI6 expression were determined by FC. In the absence or presence of dinutuximab, NK-92MI ${ }^{\text {hCD I6-GFP }}$ cells were cocultured with a constant number of Y79 (C), WERI-Rb-I (D), RBJY (E) and SNPH-Rb-C24 (F) cells at E:T ratio of I:I, 5:I, and I0:I. The supernatants were collected for the LDH release assay by a colorimetric reaction. Numerical values denote the mean \pm SD of three independent experiments. ${ }^{*} \mathrm{p}<0.05,{ }^{* *} \mathrm{p}<0.01$, and ${ }^{* * *} \mathrm{p}<0.00$ I by Student's $t$-test. 
A

Y79
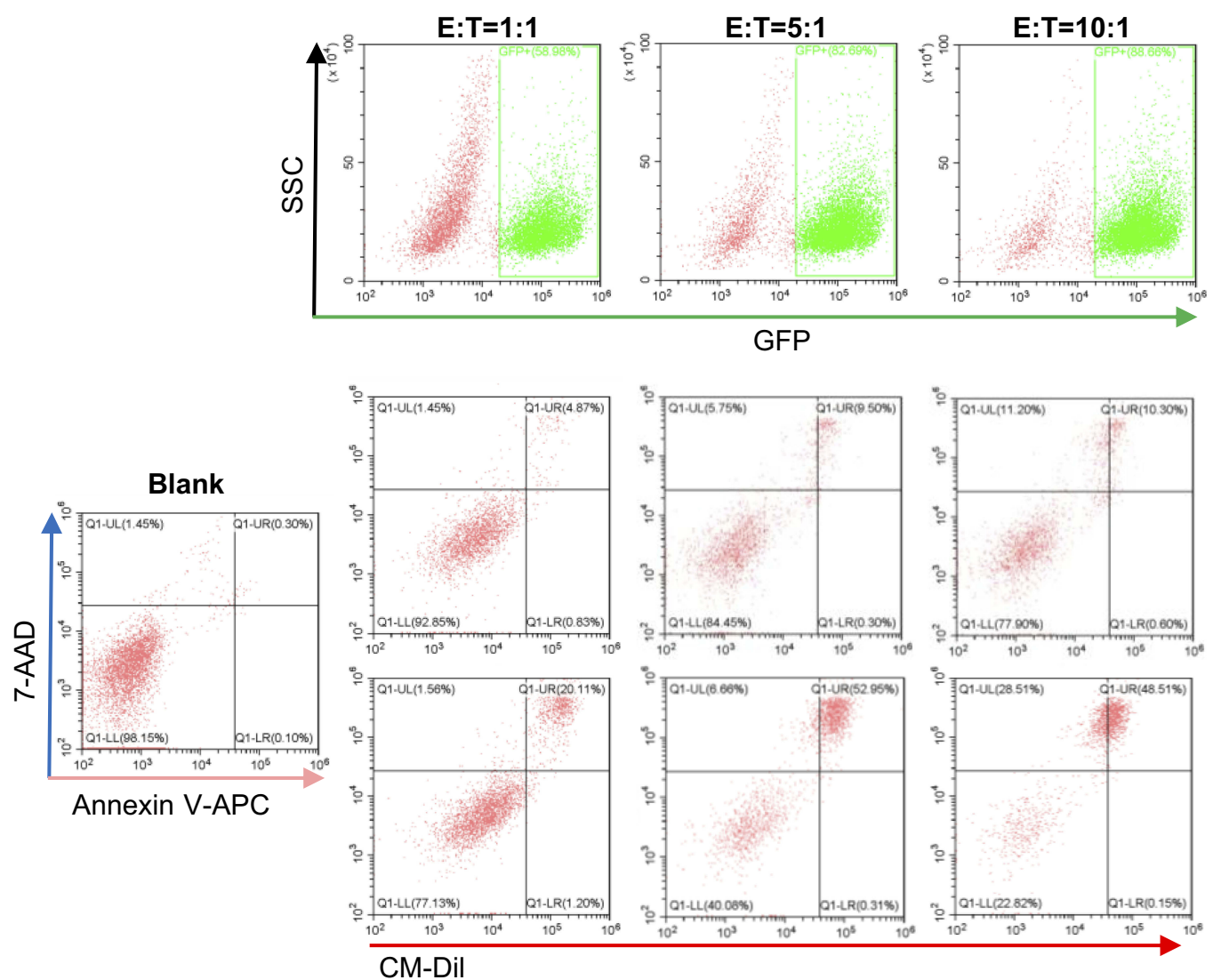

B

Y79
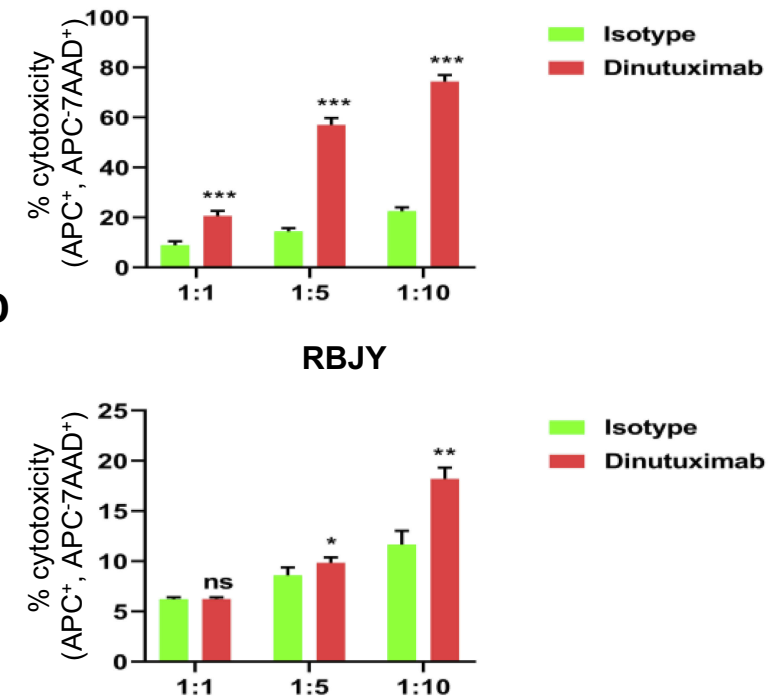

C

WERI-Rb-1
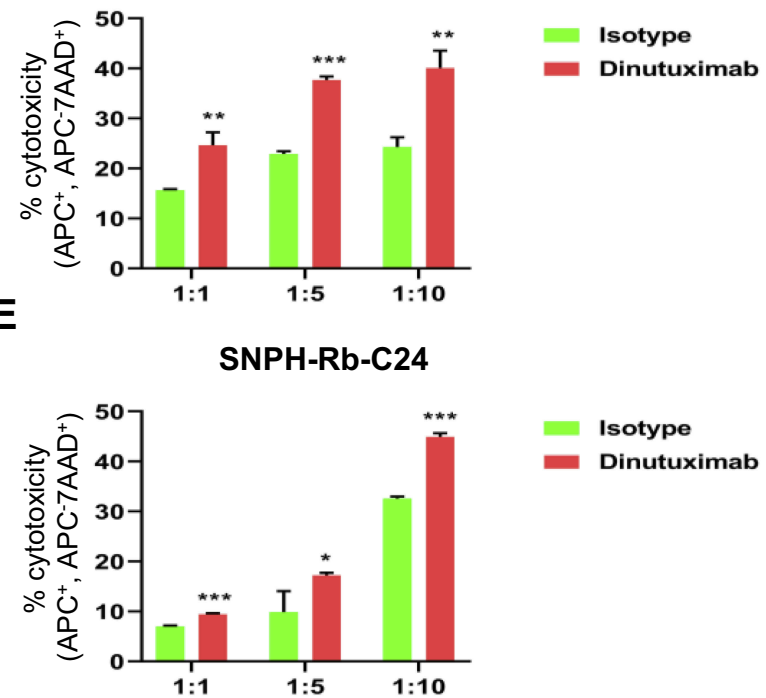

Figure 5 Dinutuximab increases the apoptosis of retinoblastoma cells by NK-92MI ${ }^{\text {hCDI6-GFP }}$ cells, as detected by FC. Retinoblastoma cells were labeled with CM-Dil. NK$92 \mathrm{MI}^{\mathrm{hCDI} \text { 6-GFP }}$ cells were cocultured with a constant number of target cells at E:T ratios of I:I, 5:I, and I0:I, without or with dinutuximab. Apoptotic and dead cells were assessed by FC using annexin V-APC and 7-AAD. (A) Representative density plots of the discrimination of effector and target cells by GFP and the cytotoxicity of NK-92MI ${ }^{\text {hCDI6-GFP }}$ cells against $Y 79$ cells at various E:T ratios in the absence or presence of dinutuximab. (B-E) Cytotoxicity of NK-92MI ${ }^{\text {hCDI6-GFP }}$ cells toward Y79, WERI-Rb-I, RBJY and SNPH-Rb-C24 cells labeled with CM-Dil. Numerical values denote the mean \pm SD of three separate experiments. ns: not significant; ${ }^{*} p<0.05$, ${ }^{* *} p<0.0$ I, and ${ }^{* * * *} p<0.00$ I by Student's $t$-test. 
top panel). Similar to the results of the LDH release assays, the apoptosis assay showed the remarkable ADCC of NK-92MI ${ }^{\text {hCD16-GFP }}$ cells against Y79, WERI-Rb-1 cells and moderate cytotoxicity against primary SNPH-Rb-C24 cells in the presence of dinutuximab (Figure 5A-C, E, S5A and $\underline{\mathrm{C}}$ ). However, this improvement was not as obvious as that toward primary RBJY cells (Figure 5D and S5B). Taken together, our data strongly indicate that dinutuximab-dependent NKmediated cytotoxicity plays a crucial role in enhancing the cytotoxicity of $\mathrm{NK}-92 \mathrm{MI}^{\mathrm{hCD} 16-\mathrm{GFP}}$ cells against retinoblastoma cells.

\section{Dinutuximab Augments the Cytotoxic Function of NK-92MI ${ }^{\text {hCDI6-GFP }}$ Cells Toward Retinoblastoma by Upregulating the Perforin-Granzyme B Pathway}

To determine the mechanism of the enhanced cytotoxicity of NK-92MI ${ }^{\text {hCD16-GFP }}$ cells against retinoblastoma cells in the presence of dinutuximab, different retinoblastoma cells were preincubated with dinutuximab or the isotype control and then cocultured with $\mathrm{NK}-92 \mathrm{MI}^{\mathrm{hCD} 16-\mathrm{GFP}}$ cells at the E/T ratio of 10:1. Six hours later, the supernatants were collected for ELISAs on perforin and granzyme B. The results showed that dinutuximab contributed to a remarkable increase in the production of both perforin and granzyme B from NK-92MI ${ }^{\text {hCD16-GFP }}$ cells when stimulated by targets compared to the isotype control (Figure 6A and B). Thus, our data indicate that enhanced ADCC toward retinoblastoma cells is partially attributed to the upregulation of the perforingranzyme cytolytic pathway of NK cells.

\section{NK-92MI ${ }^{\text {hCDI6-GFP }}$ Cell Activation Is Mediated by Increased CD 107a Expression}

CD107a, whose increase indicates cytotoxic NK cell degranulation, lines the membrane of perforin-granzyme granules. To determine the change in CD107a expression following degranulation, $\mathrm{NK}-92 \mathrm{MI}^{\mathrm{hCD} 16-\mathrm{GFP}}$ cells were cocultured with an equal number of retinoblastoma cells respectively for $6 \mathrm{~h}$ in the presence or absence of dinutuximab. CD107a expression in NK-92MI ${ }^{\text {hCD16-GFP }}$ cells was detected by FC. Baseline CD107a expression in NK$92 \mathrm{MI}^{\mathrm{hCD} 16-\mathrm{GFP}}$ cells was quite low (Figure 6D). With stimulation from retinoblastoma cells, dinutuximab obviously promoted CD107a expression in NK92MI ${ }^{\text {hCD16-GFP }}$ cells (Figure 6C). Three separate assays showed that Y79 cells were the strongest stimulation NK-92MI ${ }^{\text {hCD16-GFP }}$ cells to express CD107a (53.95 \pm $2.59 \%$ vs $28.75 \pm 0.57, \mathrm{p}=0.0003$ ), compared to WERI$\mathrm{Rb}-1$ cells $(44.45 \pm 1.22 \%$ vs $32.20 \pm 0.08, \mathrm{p}=0.0003)$, primary RBJY cells $(38.9 \pm 0.51$ vs $33.27 \pm 0.11$, $\mathrm{p}=0.0002$ ), and primary SNPH-Rb-C24 cells (45.97 \pm $2.58 \%$ vs $22.57 \pm 5.70, \mathrm{p}=0.0029$ ) (Figure $6 \mathrm{E}$ ). Collectively, our findings indicate that the increased proportion of CD107a-expressing $\mathrm{NK}-92 \mathrm{MI}^{\mathrm{hCD} 16-\mathrm{GFP}}$ cells concurrent with enhanced degranulation contributes to dinutuximab-dependent cell-mediated cytotoxicity toward retinoblastoma cells.

All the above results led us to propose a killing model of NK-92MI ${ }^{\text {hCD16-GFP }}$ cells and dinutuximab to retinoblastoma cells (Figure 7). In the absence of dinutuximab, NK-92MI ${ }^{\text {hCD16-GFP }}$ cells can induce weak apoptosis and necrosis of retinoblastoma cells through intrinsic active receptors on $\mathrm{NK}-92 \mathrm{MI}^{\mathrm{hCD} 16-\mathrm{GFP}}$ cells and minimum perforin and granzyme B released by NK-92MI ${ }^{\text {hCD16-GFP }}$ cells (Figure 7A). Dinutuximab can bridge GD2 on the retinoblastoma cells and CD16 on the NK-92MI ${ }^{\text {hCD16-GFP }}$ cells, which triggers intense ADCC and causes massive death of retinoblastoma cells. Meanwhile, CD107a upregulated on the membrane of $\mathrm{NK}-92 \mathrm{MI}^{\mathrm{hCD} 16-\mathrm{GFP}}$ cells accompanying degranulation protects $\mathrm{NK}-92 \mathrm{MI}^{\mathrm{hCD} 16-\mathrm{GFP}}$ cells from autolysis (Figure 7B).

\section{Discussion}

Among the major obstacles of acquiring effective targeted cancer therapies is the lack of specific targets. Although researchers have examined GD2 and GD2 synthase expression in retinoblastoma since 1993, previous studies focused on their diagnostic use for disseminated diseases in bone marrow and cerebrospinal fluid. ${ }^{17}$ Our study examined GD2 expression in retinoblastoma patients with clinical information for further analysis. After consulting the relevant literature, we concluded that the scale of research on GD2 staining was the largest among non-Caucasian populations. Intriguingly, we also examined 5 adult patients who were over the age of 20 at diagnosis, whose tumor may have originated from retinocytoma, but there was nothing unique about the GD2 expression pattern in these adult-onset retinoblastoma patients. ${ }^{62}$ According to our study, GD2 is highly restricted to the membrane of retinoblastoma cells, with a $37 \%$ positive rate, which thus indicates the possibility of GD2 as a potential immunotherapeutic target for retinoblastoma. In line with previous work, the heterogeneous GD2 expression pattern among the positively stained samples 
A

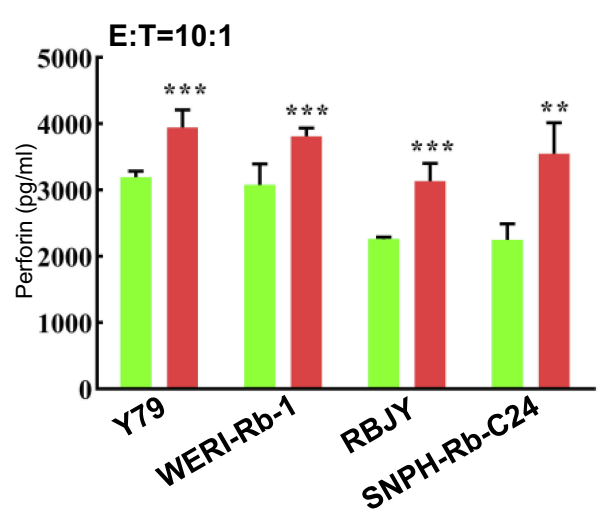

B

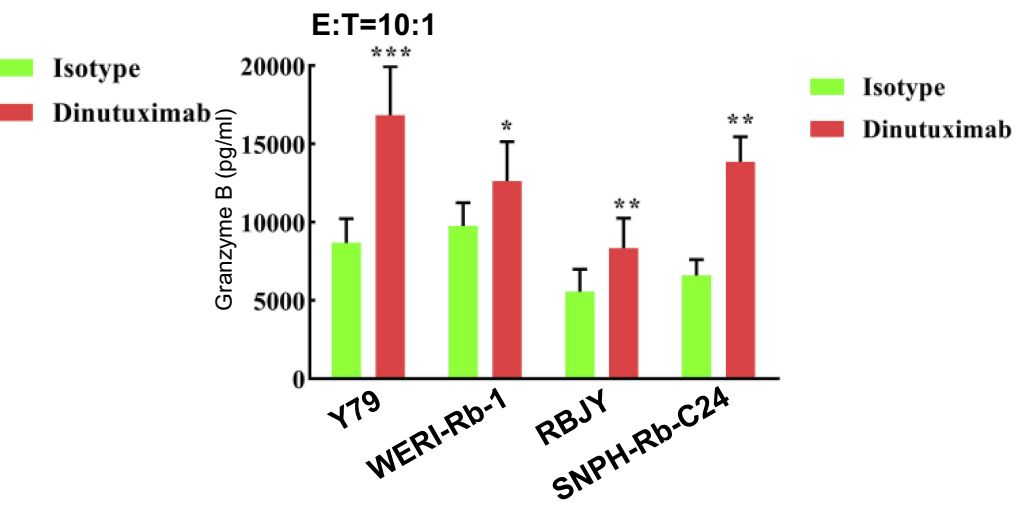

C
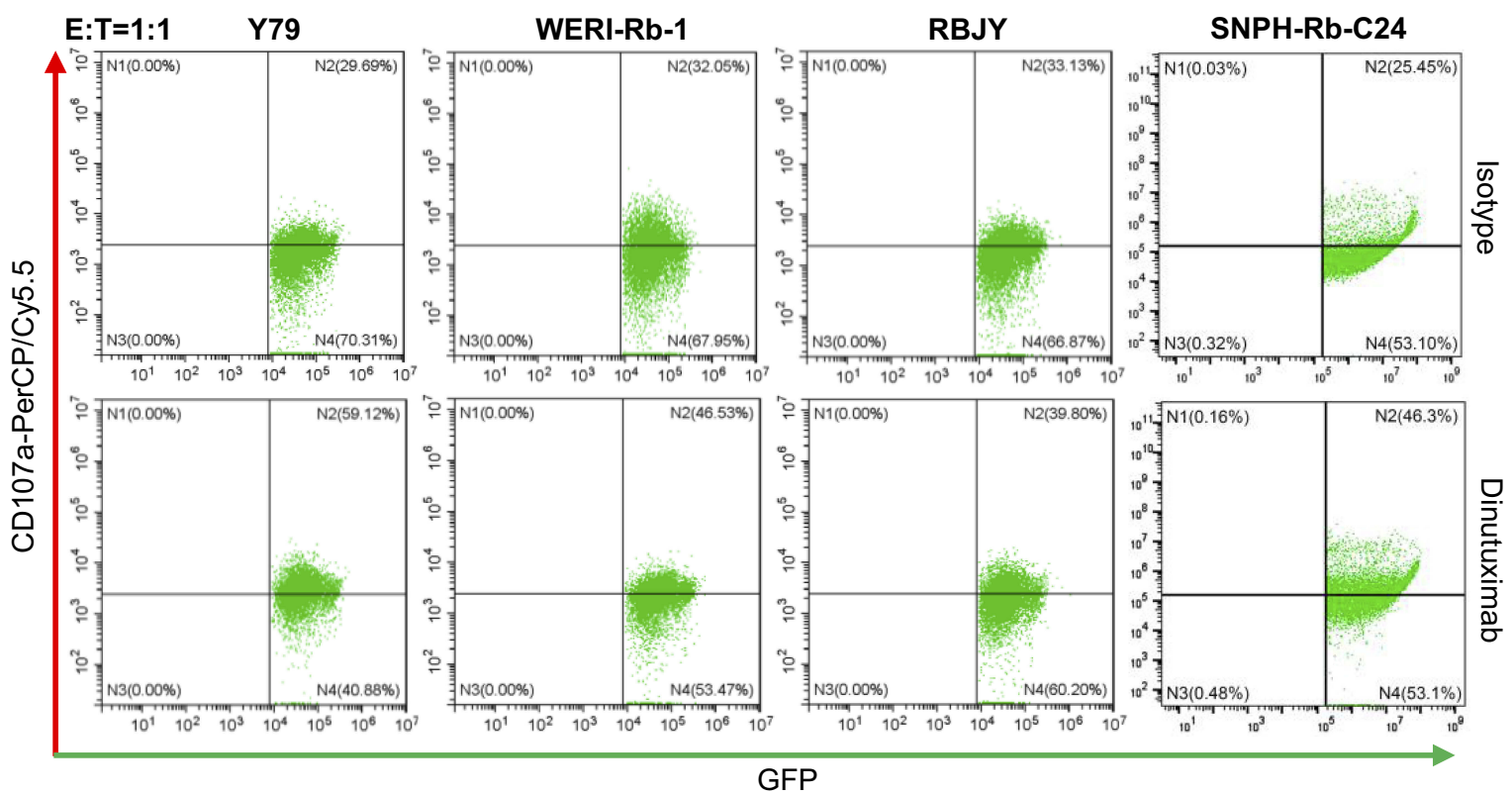

GFP

D

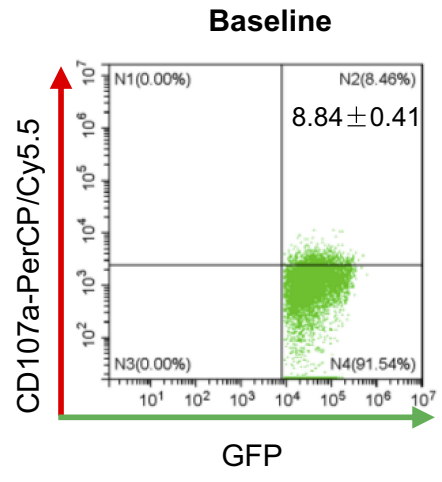

E

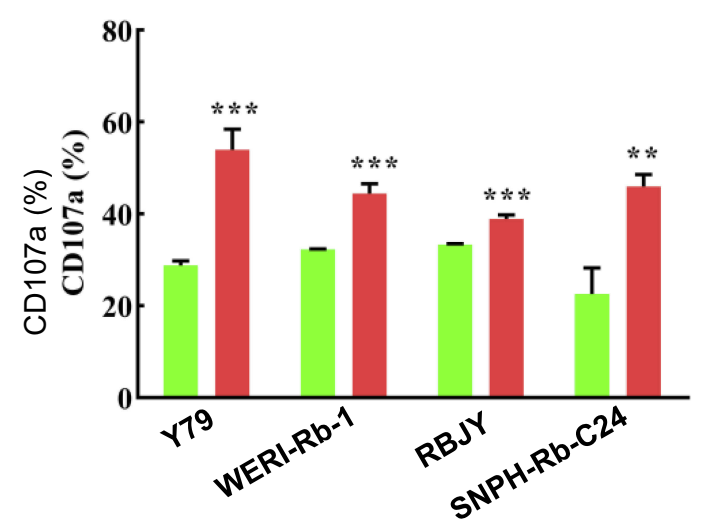

Figure 6 Dinutuximab augments the cytotoxicity of NK-92MI ${ }^{\text {hCD I6-GFP }}$ cells against retinoblastoma cells by increasing perforin-granzyme B release and CD I07a expression. (A, B) NK$92 \mathrm{MI}^{\text {hCDI6-GFP }}$ cells were cocultured with a constant number of retinoblastoma cells for 6 hours at an E:Tratio of I0:I in the absence or presence of dinutuximab. The supernatants were collected to detect perforin $(\mathbf{A})$ and granzyme B (B) by ELISAs. (C) NK-92MI ${ }^{\text {hCDI6-GFP }}$ cells were cocultured with retinoblastoma cells at an E:T ratio of I:I for 3 hours with or without dinutuximab, followed by the addition of monensin for an additional incubation lasting 3 hours. CDI07a was measured in GFP-gated NK-92MI ${ }^{\text {hCDI6-GFP }}$ cells by FC. Representative

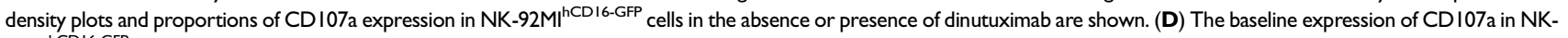
$92 \mathrm{MI}^{\text {hCDI6-GFP }}$ cells, results of three independent experiments are denoted as the mean \pm SD on the density plot. (E) Quantitation of (C). Numerical values denote the mean \pm SD of three independent experiments. ${ }^{*} p<0.05$, **p $<0.01$, and ${ }^{*} * *_{p}<0.001$ by Student's $t$-test. 
A

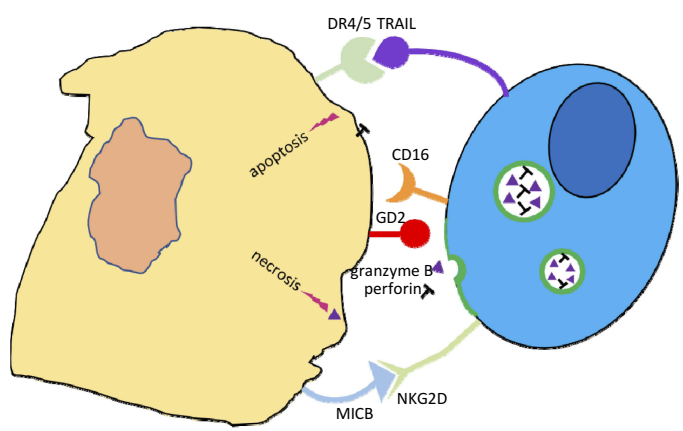

Retinoblastoma

NK-92MIhCD16-GFP
B

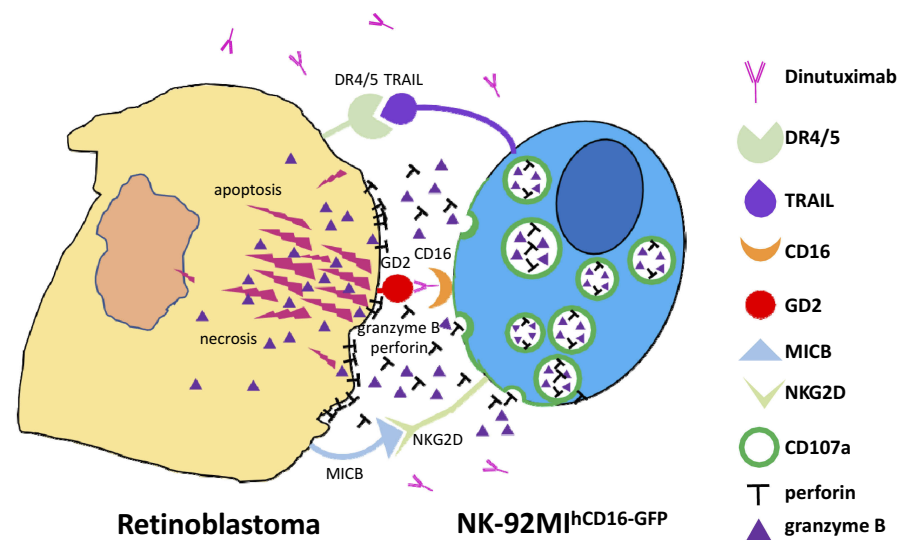

Figure 7 A proposed killing model of NK-92MI ${ }^{\text {hCDI6-GFP }}$ cells and dinutuximab to retinoblastoma cells. (A) NK-92MI ${ }^{\text {hCDI6-GFP }}$ cells are able to induce weak apoptosis and necrosis of retinoblastoma cells through intrinsic active receptors on NK-92MI ${ }^{\text {hCDI6-GFP }}$ cells and minimum perforin and granzyme B released by NK-92MI ${ }^{\text {hCDI6-GFP }}$ cells. (B) Dinutuximab acts as the bridge of GD2 on the retinoblastoma cells and CDI6 on the NK-92MI ${ }^{\text {hCDI6-GFP }}$ cells, which triggers intense ADCC and leads to massive death of retinoblastoma cells, meanwhile, CDI07a protects NK-92MI ${ }^{\text {hCDI6-GFP }}$ cells from cytotoxic granules.

further supported the multifocal origin and different cytogenetic clones within one tumor, and this positively stained population may be the seed of minimal disseminated disease in bone marrow and cerebrospinal fluid if it survives from intense chemotherapy and/or radiotherapy. ${ }^{17,19,63}$ However, only one of the four patients with posttherapeutic metastasis was GD2 positive (IRS 8). One plausible explanation is that the percentage or intensity of GD2-positive cells is under the detection threshold, but this proportion of cells may exert stem cell-like properties and ultimately settle down in the niche of bone marrow or cerebrospinal fluid after chemotherapeutic selection. ${ }^{12,64}$ This hypothesis is also supported by the fact that metastasized retinoblastomas were almost GD2 positive. ${ }^{16,19}$ This hypothesis may also partially explain the $40 \%$ GD2 staining rate among 5 patients with late recurrence. Our further analysis of the intrinsic relationship between the GD2 expression pattern and tumor stage as well as the proliferation index suggests that GD2 expression may indicate a poor prognosis. Thus, we may conclude that GD2-positive high-risk retinoblastoma patients, especially those with a high IRS, should be under a more systematic examination and a closer follow-up.

The activated immune system, which includes active NK cells, is indispensable for tumor destruction and metastasis prevention, as evidenced by pooled studies. However, tumor cells have developed dozens of strategies to escape from immunosurveillance and retain an immunosuppressive microenvironment. ${ }^{65}$ Tumor-infiltrating immune cells, as indicated by the immunohistochemical and/or immunocytochemical analysis of retinoblastoma tissues and vitreous bodies, supported BRB destruction by aggressive retinoblastoma cells and a disturbance in immune homeostasis. Deep sequencing-based transcriptome profiling analysis of the retinoblastoma and paired retina specimens further confirmed the complement system, inflammatory response, and IL-6/JAK/STAT3 axis as the most influenced pathways of immune modulation in the retinoblastoma microenvironment. In the past, it was thought that tumor cells caused activation of the complement system, which was beneficial to patients; however, recent studies indicated that complement activation promoted the development of cancer and that drugs which inhibited complement activation exerted antitumor effects. ${ }^{66-69}$ Disturbed complement homeostasis paves the way for tumor growth and metastasis by recruiting immunosuppressive myeloid-derived stem cells (MDSCs), macrophages, and mast cells and impeding $\mathrm{T}$ cells from eliminating tumors. ${ }^{68,70-73}$ The development of most cancers is accompanied by overactivation of the IL-6/JAK/ STAT3 signaling pathway, which indicates a poor prognosis. Studies have found that STAT3 cab negatively regulate the functions of immune cells, including inhibiting the function of NK cells and T cells, inhibiting the maturation of dendritic cells, and promoting the expansion of Treg cells and MDSCs. ${ }^{74,75}$ Moreover, STAT3 could also induce the production of immunosuppressive factors, such as IL-10 and TGF $\beta$, in the tumor microenvironment. ${ }^{75}$ The concept that chronic inflammation promoted tumor onset and progression was first suggested in the middle 1800s by the German pathologist Rudolf Virchow. Chronic inflammation accelerates the initiation and progression of tumors through inflammatory cells and mediators (including 
cytokines, chemokines, and prostaglandins). ${ }^{76}$ For example, IL-6, which is highly expressed in the tumor microenvironment, is a bridge between chronic inflammation and immunosuppression. ${ }^{75}$ Further GSEA with the GO term "innate immune response" showed the negatively regulated innate immune response, chaos of cytokine regulation and dysregulated NK cell-mediated immunity. The results of the GSEA, the high-risk pathological features, and the tumor-bearing clinical status all suggest that immunosuppression overrides immunosurveillance in advanced retinoblastoma patients, but the accurate distinction between cancer-promoting and anticancer components in locally infiltrating leukocytes demands more precise phenotyping of various immune cells through multiplex immunofluorescence, mass cytometry CyTOF or singlecell transcriptomic analyses.

NK cells are a major component of innate immunity, and NK-based therapeutic strategies have achieved encouraging anticancer effects. ${ }^{27,77}$ IL-2 is one of the most potent activators of NK cells and is also associated with severe systemic adverse effects and Treg cell activation. $^{78,79}$ As an IL-2 independent cell line, NK92MI cells express all activating receptors but lack all currently known inhibitory killer cell immunoglobulinlike receptors. ${ }^{36}$ The highly cytotoxic NK-92MI cells can kill various types of cancer, making them a good substitute for PBMC-derived NK cells due to their safety and expansion abilities. ${ }^{38,80-82}$ In this study, we creatively overexpressed CD16 on NK-92MI cells to increase dinutuximab-dependent NK-mediated cytotoxicity against retinoblastoma cell lines and primary cell cultures. The low affinity Fc $\gamma \mathrm{R}$ CD16 alone can activate NK-92MI ${ }^{\mathrm{hCD} 16-\mathrm{GFP}}$ cells via the cytoplasmic adaptor, whose subsequent activation will trigger perforin-granzyme cascades. ${ }^{77,83-85}$ The quantification of these cytokines in the blood may provide a clue on the activation of NK cells. NK-92MI ${ }^{\text {hCD16-GFP }}$ cells simultaneously became "coated" with CD107a upon degranulation, protecting themselves from newly released cytolytic granules. Perforin induces the apoptosis of target cells by activating caspase-3 and/or by directly cleaving the key caspase substrates Bid and DFFA to trigger DNA fragmentation. DNA damage by granzyme B was contributed to direct activation of DNA fragmentation factors or indirect proteolytic cleavage of executioner procaspases and subsequent formation of proapoptotic complex. ${ }^{86}$

Ohashi et al verified the cytotoxicity of PBMC-derived NK cells against retinoblastoma cell lines; however, only when further activated with chemokines were these NK cells able to show some cytotoxicity towards newly isolated primary cultures. ${ }^{45}$ In line with Ohashi's work, NK92MI ${ }^{\text {hCD16-GFP }}$ cells were quite cytotoxic against $\mathrm{Y} 79$ and WERI-Rb-1 cells, and the cytotoxicity was further amplified by the GD2-specific monoclonal antibody dinutuximab. However, our two different primary retinoblastoma cultures exerted quite different levels of sensitivity to the combination of NK-92MI ${ }^{\mathrm{hCD} 16-\mathrm{GFP}}$ cells and dinutuximab. The therapeutic strategy had a very large effect on SNPH$\mathrm{Rb}-\mathrm{C} 24$ cells, but a much smaller effect on RBJY cells. We inferred that the freshly established RBJY cell line consisted of a large proportion of stromal contents and different subclones, as evidenced by the relatively low GD2 expression. However, the SNPH-Rb-C24 cell line has been stably passaged for over 50 times accompanied by clonal selection, and its characteristics are similar to those of the Y79 and WERI-Rb-1 cell lines. This might explain the higher expression of GD2 and higher sensitivity to the combined therapy than RBJY cells. In addition to the intrinsic cytotoxicity of NK cells, another reason why NK cells are toxic to retinoblastoma cells is the high expression of MICB and death receptors $4 / 5$ and the loss of MHC-I on retinoblastoma. ${ }^{87-89}$ It has also been reported that tumor cells can escape the killing of NK cells by downregulating NKG2D activation ligands such as ULBP1-3, MICA, and MICB. ${ }^{90}$ The death receptors transduce the proapoptotic signal from TRAIL and TNF $\alpha .{ }^{91}$ It is generally accepted that the aberrantly low expression of MHC-I gives rise to immune escape from cytotoxic $\mathrm{T}$ cells and the immune activation of NK cells.

\section{Conclusion}

Our research suggests that both GD2 synthase and GD2 are highly expressed in the tumor mass of high-risk retinoblastoma patients and indicate an advanced stage and faster proliferation of tumor cells. If the pathology shows GD2 expression, a close follow-up should be conducted among this population. In addition, our in vitro study also shows the combination of CD16-expressing NK-92MI cells and dinutuximab has potent cytotoxicity against retinoblastoma cells and primary cell cultures. However, animal experiments are further needed as the basis of a clinal trial of dinutuximab and/or adoptive NK cell transfer therapy on retinoblastoma patients.

\section{Acknowledgments}

This work was supported by the National Natural Science Foundation of China (81772875, 81770961, U1932135, 
81802702, 81702781) and The Science and Technology Commission of Shanghai (17DZ2260100 and 19JC14 10200).

\section{Disclosure}

The authors report no conflicts of interest in this work.

\section{References}

1. Dyer MA. Lessons from retinoblastoma: implications for cancer, development, evolution, and regenerative medicine. Trends $\mathrm{Mol}$ Med. 2016;22(10):863-876. doi:10.1016/j.molmed.2016.07.010

2. Truong B, Green AL, Friedrich P, Ribeiro KB, Rodriguez-Galindo C. Ethnic, racial, and socioeconomic disparities in retinoblastoma. JAMA Pediatr. 2015;169(12):1096-1104. doi:10.1001/jamapediatrics.2015. 2360

3. Rajeshuni N, Whittemore AS, Ludwig CA, Mruthyunjaya P, Moshfeghi DM. Racial, ethnic, and socioeconomic disparities in retinoblastoma enucleation: a population-based study, SEER 18 2000-2014. Am J Ophthalmol. 2019. doi:10.1016/j.ajo.2019.04.015

4. Dimaras H, Kimani K, Dimba EA, et al. Retinoblastoma. Lancet. 2012;379(9824):1436-1446. doi:10.1016/S0140-6736(11)61137-9

5. Asnaghi L, White DT, Key N, et al. ACVR1C/SMAD2 signaling promotes invasion and growth in retinoblastoma. Oncogene. 2019;38 (12):2056-2075. doi:10.1038/s41388-018-0543-2

6. Chen M, Luo C, Zhao J, Devarajan G, Xu H. Immune regulation in the aging retina. Prog Retin Eye Res. 2019;69:159-172. doi:10.1016/ j.preteyeres.2018.10.003

7. Park DY, Lee J, Kim J, et al. Plastic roles of pericytes in the blood-retinal barrier. Nat Commun. 2017;8:15296. doi:10.1038/ ncomms 15296

8. Suzuki M, Cheung NK. Disialoganglioside GD2 as a therapeutic target for human diseases. Expert Opin Ther Tar. 2015;19 (3):349-362. doi:10.1517/14728222.2014.986459

9. Durbas M, Horwacik I, Boratyn E, Kamycka E, Rokita H. GD2 ganglioside specific antibody treatment downregulates PI3K/Akt/ mTOR signaling network in human neuroblastoma cell lines. Int J Oncol. 2015;47(3):1143-1159. doi:10.3892/ijo.2015.3070

10. Julien S, Bobowski M, Steenackers A, Le Bourhis X, Delannoy P. How do gangliosides regulate RTKs signaling? Cells. 2013;2 (4):751-767. doi:10.3390/cells2040751

11. Iwasawa $T$, Zhang $P$, Ohkawa $Y$, et al. Enhancement of malignant properties of human glioma cells by ganglioside GD3/ GD2. Int J Oncol. 2018;52(4):1255-1266. doi:10.3892/ijo.2018.4266

12. Battula VL, Shi Y, Evans KW, et al. Ganglioside GD2 identifies breast cancer stem cells and promotes tumorigenesis. J Clin Invest. 2012;122(6):2066-2078. doi:10.1172/JCI59735

13. Liang YJ, Ding Y, Levery SB, Lobaton M, Handa K, Hakomori SI. Differential expression profiles of glycosphingolipids in human breast cancer stem cells vs. cancer non-stem cells. Proc Natl Acad Sci U S A. 2013;110(13):4968-4973. doi:10.1073/pnas. 1302825110

14. Portoukalian J, David MJ, Gain P, Richard M. Shedding of GD2 ganglioside in patients with retinoblastoma. Int $J$ Cancer. 1993;53 (6):948-951. doi:10.1002/ijc.2910530614

15. Cheung NK, Cheung IY, Kramer K, et al. Key role for myeloid cells: Phase II results of anti-G(D2) antibody 3F8 plus granulocyte-macrophage colony-stimulating factor for chemoresistant osteomedullary neuroblastoma. Int $J$ Cancer. 2014;135(9):21 99-2205. doi:10.1002/ijc.28851

16. Shen H, Tang Y, Xu X, Tang H. Detection of the GD2+/CD56 +/CD45- immunophenotype by flow cytometry in cerebrospinal fluids from a patient with retinoblastoma. Pediatr Hematol Oncol. 2013;30(1):30-32. doi:10.3109/08880018.2012.737094
17. Laurent VE, Sampor C, Solernou V, et al. Detection of minimally disseminated disease in the cerebrospinal fluid of children with high-risk retinoblastoma by reverse transcriptase-polymerase chain reaction for GD2 synthase mRNA. Eur J Cancer. 2013;49 (13):2892-2899. doi:10.1016/j.ejca.2013.04.021

18. Laurent VE, Otero LL, Vazquez V, et al. Optimization of molecular detection of GD2 synthase mRNA in retinoblastoma. Mol Med Rep. 2010;3(2):253-259. doi:10.3892/mmr 00000248

19. Chantada GL, Rossi J, Casco F, et al. An aggressive bone marrow evaluation including immunocytology with GD2 for advanced retinoblastoma. J Pediatr Hematol Oncol. 2006;28(6):369-373. doi:10.1097/00043426-200606000-00009

20. Ho WL, Hsu WM, Huang MC, Kadomatsu K, Nakagawara A. Protein glycosylation in cancers and its potential therapeutic applications in neuroblastoma. J Hematol Oncol. 2016;9(1):100. doi:10. 1186/s13045-016-0334-6

21. Yu AL, Gilman AL, Ozkaynak MF, et al. Anti-GD2 antibody with GM-CSF, interleukin-2, and isotretinoin for neuroblastoma. $N$ Engl J Med. 2010;363(14):1324-1334. doi:10.1056/NEJMoa09 11123

22. Navid F, Sondel PM, Barfield R, et al. Phase I trial of a novel anti-GD2 monoclonal antibody, Hu14.18K322A, designed to decrease toxicity in children with refractory or recurrent neuroblastoma. J Clin Oncol. 2014;32 (14):1445-1452. doi:10.1200/JCO.2013.50.4423

23. Ladenstein R, Poetschger U, Gray J, et al. Toxicity and outcome of anti-GD2 antibody ch14.18/CHO in front-line, high-risk patients with neuroblastoma: final results of the Phase III immunotherapy randomisation (HR-NBL1/SIOPEN trial). $J$ Clin Oncol. 2016;34 (15_suppl):10500. doi:10.1200/JCO.2016.34.15_suppl.10500

24. Furman WL, Shulkin BL, Federico SM, et al. Early response rates and Curie scores at end of induction: an update from a phase II study of an anti-GD2 monoclonal antibody (mAb) with chemotherapy (CT) in newly diagnosed patients (pts) with high-risk (HR) neuroblastoma (NB). J Clin Oncol. 2017;35(15_suppl):10534. doi:10.1200/JCO.20 17.35.15_suppl.10534

25. Mody R, Naranjo A, Van Ryn C, et al. Irinotecan-temozolomide with temsirolimus or dinutuximab in children with refractory or relapsed neuroblastoma (COG ANBL1221): an open-label, randomised, Phase 2 trial. Lancet Oncol. 2017;18(7):946-957. doi:10.1016/S14702045(17)30355-8

26. Dhillon S. Dinutuximab: first global approval. Drugs. 2015;75 (8):923-927. doi:10.1007/s40265-015-0399-5

27. Lopez-Soto A, Gonzalez S, Smyth MJ, Galluzzi L. Control of metastasis by NK cells. Cancer Cell. 2017;32(2):135-154. doi:10.1016/j. ccell.2017.06.009

28. Romain G, Senyukov V, Rey-Villamizar N, et al. Antibody Fc engineering improves frequency and promotes kinetic boosting of serial killing mediated by NK cells. Blood. 2014;124(22):3241-3249. doi:10.1182/blood-2014-04-569061

29. Paul P, Picard C, Sampol E, et al. Genetic and functional profiling of CD16-dependent natural killer activation identifies patients at higher risk of cardiac allograft vasculopathy. Circulation. 2018;137 (10):1049-1059. doi:10.1161/CIRCULATIONAHA.117.030435

30. Modak S, Le Luduec JB, Cheung IY, et al. Adoptive immunotherapy with haploidentical natural killer cells and Anti-GD2 monoclonal antibody $\mathrm{m} 3 \mathrm{~F} 8$ for resistant neuroblastoma: results of a phase I study. Oncoimmunology. 2018;7(8):e1461305. doi:10.1080/2162402 X.2018.1461305

31. Tran HC, Wan Z, Sheard MA, et al. TGFbetaR1 blockade with galunisertib (LY2157299) enhances anti-neuroblastoma activity of the anti-GD2 antibody dinutuximab (ch14.18) with natural killer cells. Clin Cancer Res. 2017;23(3):804-813. doi:10.1158/1078-0432. CCR-16-1743

32. Kim S, Poursine-Laurent J, Truscott SM, et al. Licensing of natural killer cells by host major histocompatibility complex class I molecules. Nature. 2005;436(7051):709-713. doi:10.1038/nature03847 
33. Wang W, Erbe AK, Hank JA, Morris ZS, Sondel PM. NK cell-mediated antibody-dependent cellular cytotoxicity in cancer immunotherapy. Front Immunol. 2015;6:368. doi:10.3389/fimmu.20 15.00368

34. Erbe AK, Wang W, Carmichael L, et al. Neuroblastoma patients' KIR and KIR-Ligand genotypes influence clinical outcome for dinutuximab-based immunotherapy: a report from the children's oncology group. Clin Cancer Res. 2018;24(1):189-196. doi:10.1158/10780432.CCR-17-1767

35. Delgado DC, Hank JA, Kolesar J, et al. Genotypes of NK cell KIR receptors, their ligands, and Fcgamma receptors in the response of neuroblastoma patients to Hu14.18-IL2 immunotherapy. Cancer Res. 2010;70(23):9554-9561. doi:10.1158/0008-5472.CAN-10-2211

36. Boyiadzis M, Agha M, Redner RL, et al. Phase 1 clinical trial of adoptive immunotherapy using "off-the-shelf" activated natural killer cells in patients with refractory and relapsed acute myeloid leukemia. Cytotherapy. 2017;19(10):1225-1232. doi:10.1016/j.jcyt.2017.07.008

37. Tonn T, Schwabe D, Klingemann HG, et al. Treatment of patients with advanced cancer with the natural killer cell line NK-92. Cytotherapy. 2013;15(12):1563-1570. doi:10.1016/j.jcyt.2013.06.017

38. Arai S, Meagher R, Swearingen M, et al. Infusion of the allogeneic cell line NK-92 in patients with advanced renal cell cancer or melanoma: a phase I trial. Cytotherapy. 2008;10(6):625-632. doi:10.10 $80 / 14653240802301872$

39. Maki G, Klingemann HG, Martinson JA, Tam YK. Factors regulating the cytotoxic activity of the human natural killer cell line, NK-92. J Hematother Stem Cell Res. 2001;10(3):369-383. doi:10.1089/ 152581601750288975

40. Spadoni I, Fornasa G, Rescigno M. Organ-specific protection mediated by cooperation between vascular and epithelial barriers. Nat Rev Immunol. 2017;17(12):761-773. doi:10.1038/nri.2017.100

41. Chen X, Kunda PE, Lin J, et al. SYK-targeted dendritic cell-mediated cytotoxic T lymphocytes enhance the effect of immunotherapy on retinoblastoma. J Cancer Res Clin Oncol. 2018;144(4):675-684. doi:10.1007/s00432-018-2584-x

42. Liu Q, Wang Y, Wang H, Liu Y, Liu T, Kunda PE. Tandem therapy for retinoblastoma: immunotherapy and chemotherapy enhance cytotoxicity on retinoblastoma by increasing apoptosis. J Cancer Res Clin Oncol. 2013;139(8):1357-1372. doi:10.1007/s00432-013-1448-7

43. Mitra M, Kandalam M, Harilal A, et al. EpCAM is a putative stem marker in retinoblastoma and an effective target for T-cell-mediated immunotherapy. Mol Vis. 2012;18.

44. Hayashida Y, Kurimoto S, Yamamoto N. Effect of lymphokine-activated killer cells on human retinoblastoma cells (Y-79) in vitro: enhancement of the activity by a polysaccharide preparation, krestin. Biochem Biophys Res Commun. 1991;174 (1):107-114. doi:10.1016/0006-291X(91)90492-P

45. Ohashi Y, Sasabe T, Nishida T, Manabe R. Natural killer cells kill human retinoblastoma cells. Jpn J Ophthalmol. 1984;28(4):370-376.

46. Merriam JC, Lyon HS, Char DH. Toxicity of a monoclonal F(ab')2: ricinA conjugate for retinoblastoma in vitro. Cancer Res. 1984;44 (8):3178-3183.

47. Ramtohul P, Denis D, Comet A. Natural course of a retinal metastasis from colon adenocarcinoma. Ophthalmology. 2019;126(6):840. doi:10.1016/j.ophtha.2019.03.031

48. Shields CL, McMahon JF, Atalay HT, Hasanreisoglu M, Shields JA. Retinal metastasis from systemic cancer in 8 cases. JAMA Ophthalmol. 2014;132(11):1303-1308. doi:10.1001/jamaophthalmol. 2014.2406

49. Horai R, Zarate-Blades CR, Dillenburg-Pilla P, et al. Microbiotadependent activation of an autoreactive $\mathrm{T}$ cell receptor provokes autoimmunity in an immunologically privileged site. Immunity. 2015;43(2):343-353. doi:10.1016/j.immuni.2015.07.014

50. Rosenbaum JT, McDevitt HO, Guss RB, Egbert PR. Endotoxininduced uveitis in rats as a model for human disease. Nature. 1980;286(5773):611-613. doi:10.1038/286611a0
51. Fernandez-Diaz AB, Garcia-Medina A, Ferrer-Guillen B, Berrocal A. Eye immune privilege? Nivolumab plus ipilimumab: successful treatment in a patient with cutaneous melanoma and ocular metastases. Melanoma Res. 2019;29(3):345-347. doi:10.1097/CMR.00000000 00000591

52. Pe'er J, Rowe JM, Frenkel S, Dann EJ. Testicular lymphoma, intraocular (vitreoretinal) lymphoma, and brain lymphoma: involvement of three immunoprivileged sites in one patient. Am J Hematol. 2010;85 (8):631-633. doi:10.1002/ajh.21767

53. Yuan X, He X, Li Y, et al. Establishment and genomic characterization of a novel retinoblastoma cell line without RB1 mutation derived from a Han Chinese donor. J Shanghai Jiao Tong Univ. 2018;38:866-873.

54. Fan X, Rai A, Kambham N, et al. Endometrial VEGF induces placental sFLT1 and leads to pregnancy complications. J Clin Invest. 2014;124(11):4941-4952. doi:10.1172/JCI76864

55. Wahl S, Drong A, Lehne B, et al. Epigenome-wide association study of body mass index, and the adverse outcomes of adiposity. Nature. 2017;541(7635):81-86. doi:10.1038/nature20784

56. Olin A, Henckel E, Chen Y, et al. Stereotypic immune system development in newborn children. Cell. 2018;174(5):1277-1292 e1214. doi:10.1016/j.cell.2018.06.045

57. Giugliano S, Petroff MG, Warren BD, et al. Hepatitis $C$ virus sensing by human trophoblasts induces innate immune responses and recruitment of maternal NK cells: potential implications for limiting vertical transmission. J Immunol. 2015;195(8):3737-3747. doi:10.4049/ jimmunol.1500409

58. Chai P, Jia R, Jia R, et al. Dynamic chromosomal tuning of a novel GAU1 lncing driver at chr12p13.32 accelerates tumorigenesis. Nucleic Acids Res. 2018;46(12):6041-6056. doi:10.1093/nar/gky366

59. Subramanian A, Tamayo P, Mootha VK, et al. Gene set enrichment analysis: a knowledge-based approach for interpreting genome-wide expression profiles. Proc Natl Acad Sci U S A. 2005;102 (43):15545-15550. doi:10.1073/pnas.0506580102

60. Boulagnon C, Ducasse A, Patey M, Diebold MD, Arndt C. Cytopathology of vitreous humor samples in routine practice. Acta Cytol. 2016;60(1):65-73. doi:10.1159/000444576

61. Narumi M, Nishitsuka K, Yamakawa M, Yamashita H. A survey of vitreous cell components performed using liquid-based cytology. Acta Ophthalmol. 2015;93(5):e386-390. doi:10.1111/aos.12623

62. Eagle RC Jr., Shields JA, Donoso L, Milner RS. Malignant transformation of spontaneously regressed retinoblastoma, retinoma/retinocytoma variant. Ophthalmology. 1989;96(9):1389-1395. doi:10.1016/ S0161-6420(89)32714-X

63. Yu J, Wu X, Yan J, et al. Anti-GD2/4-1BB chimeric antigen receptor $\mathrm{T}$ cell therapy for the treatment of Chinese melanoma patients. J Hematol Oncol. 2018;11(1):1. doi:10.1186/s13045-017-0548-2

64. Khosravi A, Shahrabi S, Shahjahani M, Saki N. The bone marrow metastasis niche in retinoblastoma. Cell Oncol (Dordr). 2015;38 (4):253-263. doi:10.1007/s13402-015-0232-x

65. Mohme M, Riethdorf S, Pantel K. Circulating and disseminated tumour cells - mechanisms of immune surveillance and escape. Nat Rev Clin Oncol. 2017;14(3):155-167. doi:10.1038/nrclinonc.2016.144

66. Su S, Chen J, Yao H, et al. CD10+GPR77+ cancer-associated fibroblasts promote cancer formation and chemoresistance by sustaining cancer stemness. Cell. 2018;172(4):841-856.e816. doi:10.1016/j.cell.2018.01. 009

67. Boire A, Zou Y, Shieh J, Macalinao DG, Pentsova E, Massague J. Complement component 3 adapts the cerebrospinal fluid for leptomeningeal metastasis. Cell. 2017;168(6):1101-1113 e1113. doi:10.10 16/j.cell.2017.02.025

68. Vadrevu SK, Chintala NK, Sharma SK, et al. Complement c5a receptor facilitates cancer metastasis by altering T-cell responses in the metastatic niche. Cancer Res. 2014;74(13):3454-3465. doi:10.11 58/0008-5472.CAN-14-0157 
69. Bonavita E, Gentile S, Rubino M, et al. PTX3 is an extrinsic oncosuppressor regulating complement-dependent inflammation in cancer. Cell. 2015;160(4):700-714. doi:10.1016/j.cell.2015.01.004

70. Ajona D, Ortiz-Espinosa S, Pio R, Lecanda F. Complement in metastasis: a comp in the camp. Front Immunol. 2019;10:669. doi:10.3389/ fimmu.2019.00669

71. Markiewski MM, DeAngelis RA, Benencia F, et al. Modulation of the antitumor immune response by complement. Nat Immunol. 2008;9(11):1225-1235. doi:10.1038/ni.1655

72. Medler TR, Murugan D, Horton W, et al. Complement C5a fosters squamous carcinogenesis and limits $\mathrm{T}$ cell response to chemotherapy. Cancer Cell. 2018;34(4):561-578 e566. doi:10.1016/j.ccell.2018.09.003

73. Wang Y, Sun SN, Liu Q, et al. Autocrine complement inhibits IL10-dependent T-cell-mediated antitumor immunity to promote tumor progression. Cancer Discov. 2016;6(9):1022-1035. doi:10.11 58/2159-8290.CD-15-1412

74. Gotthardt D, Putz EM, Straka E, et al. Loss of STAT3 in murine NK cells enhances NK cell-dependent tumor surveillance. Blood. 2014;124(15):2370-2379. doi:10.1182/blood-2014-03-564450

75. Johnson DE, O'Keefe RA, Grandis JR. Targeting the IL-6/JAK/ STAT3 signalling axis in cancer. Nat Rev Clin Oncol. 2018;15 (4):234-248. doi:10.1038/nrclinonc.2018.8

76. Crusz SM, Balkwill FR. Inflammation and cancer: advances and new agents. Nat Rev Clin Oncol. 2015;12(10):584-596. doi:10.1038/ nrclinonc. 2015.105

77. Dai HS, Griffin N, Bolyard C, et al. The Fc domain of immunoglobulin is sufficient to bridge NK cells with virally infected cells. Immunity. 2017;47(1):159-170 e110. doi:10.1016/j.immuni.2017.06.019

78. Aranda F, Buque A, Bloy N, et al. Trial watch: adoptive cell transfer for oncological indications. Oncoimmunology. 2015;4(11):e1046673. doi:10.1080/2162402X.2015.1046673

79. Vacchelli E, Aranda F, Bloy N, et al. Trial Watch-Immunostimulation with cytokines in cancer therapy. Oncoimmunology. 2016;5(2): e1115942. doi:10.1080/2162402X.2015.1115942

80. Alkins R, Burgess A, Kerbel R, Wels WS, Hynynen K. Early treatment of HER2-amplified brain tumors with targeted NK-92 cells and focused ultrasound improves survival. Neuro-Oncology. 2016;18 (7):974-981. doi:10.1093/neuonc/nov318
81. Williams BA, Wang $\mathrm{XH}$, Leyton JV, et al. CD16 ${ }^{+} \mathrm{NK}-92$ and anti-CD123 monoclonal antibody prolongs survival in primary human acute myeloid leukemia xenografted mice. Haematologica. 2018;103(10):1720-1729. doi:10.3324/haematol.2017.187385

82. Hao X, Li C, Zhang Y, et al. Programmable chemotherapy and immunotherapy against breast cancer guided by multiplexed fluorescence imaging in the second near-infrared window. adv mater. 2018;30(51):e1804437. doi:10.1002/adma.201804437

83. Morvan MG, Lanier LL. NK cells and cancer: you can teach innate cells new tricks. Nat Rev Cancer. 2016;16(1):7-19. doi:10.1038/nrc.2015.5

84. Bhatnagar N, Ahmad F, Hong HS, et al. FcgammaRIII (CD16)-mediated ADCC by NK cells is regulated by monocytes and FcgammaRII (CD32). Eur J Immunol. 2014;44(11):3368-3379. doi:10.1002/eji.201444515

85. Muntasell A, Ochoa MC, Cordeiro L, et al. Targeting NK-cell checkpoints for cancer immunotherapy. Curr Opin Immunol. 2017; 45:73-81. doi:10.1016/j.coi.2017.01.003

86. Prager I, Liesche C, van Ooijen $\mathrm{H}$, et al. NK cells switch from granzyme $\mathrm{B}$ to death receptor-mediated cytotoxicity during serial killing. J Exp Med. 2019; undefined(undefined):undefined.

87. Lee EK, Jo DH, Kim JH, Yu YS, Kim KW, Kim JH. NK cell-associated antigen expression in retinoblastoma animal model. Cancer Inves. 2013;31(1):67-73. doi:10.3109/07357907.2012.743554

88. Poulaki V, Mitsiades CS, McMullan C, et al. Human retinoblastoma cells are resistant to apoptosis induced by death receptors: role of caspase- 8 gene silencing. Invest Ophth Vis Sci. 2005;46(1):358-366. doi:10.1167/iovs.04-0324

89. Madigan MC, Penfold PL, King NJ, Billson FA, Conway RM. Immunoglobulin superfamily expression in primary retinoblastoma and retinoblastoma cell lines. Oncol Res. 2002;13(2):103-111.

90. Hagmann M. A trigger of natural (and other) killers. Science. 1999;285(5428):645, 647. doi:10.1126/science.285.5428.645

91. Graves JD, Kordich JJ, Huang TH, et al. Apo2L/TRAIL and the death receptor 5 agonist antibody AMG 655 cooperate to promote receptor clustering and antitumor activity. Cancer Cell. 2014;26 (2):177-189. doi:10.1016/j.ccr.2014.04.028
OncoTargets and Therapy

\section{Publish your work in this journal}

OncoTargets and Therapy is an international, peer-reviewed, open access journal focusing on the pathological basis of all cancers, potential targets for therapy and treatment protocols employed to improve the management of cancer patients. The journal also focuses on the impact of management programs and new therapeutic agents and protocols on patient perspectives such as quality of life, adherence and satisfaction. The manuscript management system is completely online and includes a very quick and fair peer-review system, which is all easy to use. Visit http://www.dovepress.com/ testimonials.php to read real quotes from published authors. 